\title{
Mitochondria Dysfunction in Frontotemporal Dementia/Amyotrophic Lateral Sclerosis: Lessons From Drosophila Models
}

\author{
Sharifah Anoar, Nathaniel S. Woodling and Teresa Niccoli* \\ Department of Genetics, Evolution and Environment, Institute of Healthy Ageing, University College London, London, \\ United Kingdom
}

OPEN ACCESS

Edited by:

Alvaro Sanchez-Martinez, University of Cambridge, United Kingdom

Reviewed by:

Lydia Castelli,

The University of Sheffield,

United Kingdom

Diego Rincon-Limas,

University of Florida, United States

*Correspondence:

Teresa Niccoli

t.niccoli@ucl.ac.uk

Specialty section:

This article was submitted to

Neurodegeneration,

a section of the journal

Frontiers in Neuroscience

Received: 29 September 2021

Accepted: 03 November 2021

Published: 24 November 2021

Citation:

Anoar S, Woodling NS and

Niccoli T (2021) Mitochondria

Dysfunction in Frontotemporal

Dementia/Amyotrophic Lateral

Sclerosis: Lessons From Drosophila Models. Front. Neurosci. 15:786076.

doi: 10.3389/fnins.2021.786076
Frontotemporal dementia (FTD) and amyotrophic lateral sclerosis (ALS) are neurodegenerative disorders characterized by declining motor and cognitive functions. Even though these diseases present with distinct sets of symptoms, FTD and ALS are two extremes of the same disease spectrum, as they show considerable overlap in genetic, clinical and neuropathological features. Among these overlapping features, mitochondrial dysfunction is associated with both FTD and ALS. Recent studies have shown that cells derived from patients' induced pluripotent stem cells (iPSC)s display mitochondrial abnormalities, and similar abnormalities have been observed in a number of animal disease models. Drosophila models have been widely used to study FTD and ALS because of their rapid generation time and extensive set of genetic tools. A wide array of fly models have been developed to elucidate the molecular mechanisms of toxicity for mutations associated with FTD/ALS. Fly models have been often instrumental in understanding the role of disease associated mutations in mitochondria biology. In this review, we discuss how mutations associated with FTD/ALS disrupt mitochondrial function, and we review how the use of Drosophila models has been pivotal to our current knowledge in this field.

Keywords: Drosophila, neurodegeneration, mitochondria, ALS, FTD

\section{INTRODUCTION}

Frontotemporal dementia (FTD) is the second most common early onset dementia, with Amyotrophic lateral sclerosis (ALS) representing the most prevalent motor neuron disease. While the two diseases are diagnosed based on distinct sets of symptoms, recent evidence suggests that they can in fact be considered two ends of the same disease spectrum, sharing genetic risk factors and neuropathological hallmarks (Ferrari et al., 2011; Van Blitterswijk et al., 2012). 15\% of FTD patients also present with ALS, and 50\% of ALS patients go on to develop FTD. In certain familial cases, different members of the same family will go on to develop either FTD or ALS (Martinaud et al., 2005). Pathologically, both diseases are characterized by intracellular proteinaceous inclusions, most commonly formed of the DNA/RNA binding protein TDP43, although aggregates can also be composed of superoxide dismutase 1 (SOD1), fused in sarcoma (FUS) or microtubule-associated protein tau (MAPT) (Ling et al., 2013; Turner et al., 2017), amongst others. 
Amyotrophic lateral sclerosis, also called Lou Gehrig's disease, is clinically characterized by the gradual loss of upper and lower motor neurons, eventually leading to death by respiratory failure. The average life expectancy is $2-5$ years after diagnosis; however, $5-10 \%$ patients can survive up to 10 years after developing clinical symptoms (Millul et al., 2005; Mateen et al., 2010). There is no cure for ALS and the drugs that have been approved so far, such as Riluzole and Edavarone (Bensimon et al., 1994; Lacomblez et al., 1996; Pandya et al., 2013; Nguyen et al., 2018; Brown et al., 2020), only prolong life by 3-6 months (Nguyen et al., 2018). The overall global incidence of ALS is 1.59 in 100,000 people whilst the prevalence is 4.42 in 100,000 (Xu et al., 2020). The average age of onset is between 55 and 65 years of age, but for familial forms earlier ages of onset have been recorded (Orsini et al., 2015). Late-onset ALS is more prevalent in males than females, but the sex ratio is quite similar at younger ages (Manjaly et al., 2010). Sporadic ALS (sALS), in which no inherited mutation directly causes disease, accounts for $95 \%$ of cases. Conversely, familial ALS (fALS), accounting for the remaining $5 \%$ of cases, is associated with a number of genetic mutations which usually show a pattern of autosomal dominant inheritance (Byrne et al., 2011). More than 40 genes have been identified as carrying mutations causing ALS including angiogenin (ANG), matrin3 (MATR3) and vesicle-associated membrane protein (VAMP)-associated protein B (VAPB) (Alsultan et al., 2016; Gregory et al., 2020). Among these, the gene most commonly associated with pure ALS is SOD1, accounting for $20 \%$ of identified fALS cases (Orsini et al., 2015). Several other ALS-associated mutations lie in genes that have also been associated with FTD, including ataxin-2 (ATXN2), cyclin F (CCNF), Coiled-Coil-Helix-CoiledCoil-Helix Domain Containing 10 (CHCHD10), chromosome 9 opening reading frame 72 (C9orf72), Dynactin (DCTN1), FUS, Optineurin (OPTN), TAR DNA binding protein (TARDBP or TDP-43), TANK-binding Kinase (TBK1), T cell-restricted intracellular antigen-1 (TIA1), Tubulin alpha 4A (TUBA4A) and valosin-containing protein (VCP) (Orr, 2011; Orsini et al., 2015; Greaves and Rohrer, 2019; Table 1). The intronic hexanucleotide repeat expansion (GGGGCC) in the C9orf72 gene (C9), is the most common genetic cause of both ALS and FTD, despite being identified only a decade ago (DeJesus-Hernandez et al., 2011; Renton et al., 2011).

Frontotemporal dementia, also called Frontotemporal Lobar Degeneration (FTLD) and formerly known as Pick's disease, is a common early onset dementia (Ling et al., 2013). The prevalence is $15-22$ per 100,000 individuals and the incidence is 2.7-4.1 per 100,000 individual per year (Onyike and DiehlSchmid, 2013). The age of onset for FTD is usually below the age of 65 (Mercy et al., 2008; Seltman and Matthews, 2012). Clinically, FTD is characterized by atrophy of the frontal or temporal lobes and, depending on the initial presenting symptom, can been categorized as behavioral variant FTD (bvFTD) if associated with changes of personality or behavior, or primary progressive aphasia (PPA) if associated with language impairment (Seltman and Matthews, 2012; Van Langenhove et al., 2012; Warren et al., 2013). There is no cure to date and no approved drugs to treat symptoms specific to this disease
(Seltman and Matthews, 2012). The sporadic form of FTD accounts for $70 \%$ of cases, whilst familial forms accounts for $30 \%$ of the cases (Turner et al., 2017). The major genes linked with FTD are C9orf72, MAPT, progranulin (GRN) and chromatin modifying protein 2B (CHMP2B) (Turner et al., 2017; Casterton et al., 2020). Less common mutations have also been found in VCP, Sequestosome 1 (SQSTM1), OPTN and ubiquilin-2 (UBQLN2) (Table 1).

An increasing array of cellular processes have been linked to the development of both ALS and FTD (Mejzini et al., 2019; Liscic et al., 2020). One of the first mechanisms implicated in ALS development was excitotoxicity, caused by inappropriate elevation of intracellular sodium and calcium levels in response to sustained neuronal stimulation (reviewed in King et al., 2016). This disease mechanism is targeted by Riluzole, which blocks sodium currents and therefore reduces neuronal excitability. In the clinic, however, Riluzole only increases lifespan of ALS patients by a few months (Nguyen et al., 2018). More recent studies, fueled by the identification of a growing number of risk genes, have implicated other cellular pathways that could represent alternative therapeutic targets. For instance, many of the mutations associated with FTD/ALS fall in genes implicated in protein degradation and vesicle transport; impairments in these pathways could potentially underlie the observed accumulation of protein deposits in patients' brains (for a review see Shahheydari et al., 2017). Similarly, impairments in RNA metabolism have been implicated by the RNA binding function of the disease-associated proteins TDP-43 and FUS. These proteins both translocate to the cytoplasm in disease, leading to disruptions in transcription and splicing (Lagier-Tourenne et al., 2010; Mackenzie et al., 2010). In addition, RNA metabolism dysfunction has also been linked to other disease-associated mutations such as C9 (Cooper-Knock et al., 2014). A number of other cellular processes are also disrupted: nucleocytoplasmic transport defects (Kim and Taylor, 2017; Fallini et al., 2020), impaired DNA repair (Sun et al., 2020), axonal transport defects, and cytoskeletal disorganization have all been described (Bilsland et al., 2010; Alami et al., 2014).

Increasingly, mitochondrial dysfunction has been implicated in disease progression: several FTD/ALS linked proteins (described in detail below) interact with mitochondria (Bannwarth et al., 2014; Tsai et al., 2020), and findings from both patient tissue and animal models link mitochondria dysfunction to FTD/ALS pathogenesis (Bannwarth et al., 2014; Nakaya and Maragkakis, 2018; Tsai et al., 2020). Moreover, mitochondrial impairments have been associated with other neurodegenerative diseases such as Alzheimer's disease (AD) and Parkinson's disease (PD) (Bosetti et al., 2002; Abou-Sleiman et al., 2006; Anandatheerthavarada and Devi, 2007; Cozzolino and Carrì, 2012), potentially suggesting some common pathogenicity across multiple disorders.

Neurons appear to be particularly susceptible to mitochondrial defects because of their high energetic demands (which almost exclusively have to be met by oxidative phosphorylation), their unique architecture with extremely long processes (axons can be longer than $1 \mathrm{~m}$ in humans), and the fact they are extremely long-lived post-mitotic cells which cannot 
dilute out defective organelles by cell division. The high energetic demands of neurons are evident from the fact that the human brain contains about $2 \%$ of the body mass but requires about $20 \%$ of the oxygen consumption and energy needs of the whole body (Seager et al., 2020). As mitochondria are the main ATP producer within a cell (Figure 1), neurons have an abundance of mitochondria to meet their ATP requirements, which allow them to perform various cellular functions and activities (Kann and Kovács, 2007). If mitochondrial function is impaired, ATP production is not only diminished, but impaired oxidative phosphorylation (OXPHOS) can also generate inappropriately high concentrations of reactive oxygen species (ROS) that can further damage mitochondria (Bhatti et al., 2017) and eventually lead to neuronal death.

TABLE 1 | Major genes associated with ALS and FTD

\begin{tabular}{|c|c|c|c|c|c|c|}
\hline Locus & Genes & ALS/FTD & Gene frequency & Mutations & Protein inclusions & Sources \\
\hline $14 q 11.2$ & ANG & ALS & $<1 \%$ ALS & Missense & TDP43 & Greenway et al., 2006 \\
\hline $5 q 31.2$ & MATR3 & ALS & $\begin{array}{l}1 \% \text { sALS } \\
1-2 \% \text { fALS }\end{array}$ & Missense & TDP43 & $\begin{array}{l}\text { Johnson et al., 2014; Nguyen } \\
\text { et al., } 2018\end{array}$ \\
\hline $21 \mathrm{q} 22.11$ & SOD1 & ALS & $\begin{array}{l}5 \% \text { sALS } \\
20 \% \text { fALS }\end{array}$ & Missense & SOD1/p62 & $\begin{array}{l}\text { Rosen et al., 1993; Shaw et al., } \\
1998\end{array}$ \\
\hline $20 q 13.32$ & VAPB & ALS & $<1 \%$ ALS & Missense & & $\begin{array}{l}\text { Nishimura et al., 2004; } \\
\text { Millecamps et al., } 2010\end{array}$ \\
\hline $12 q 24.12$ & ATXN2 & ALS-FTD & $4.7 \%$ ALS & CAG repeat & TDP-43 & $\begin{array}{l}\text { Elden et al., 2010; Bäumer } \\
\text { et al., 2014; Rubino et al., } 2019\end{array}$ \\
\hline 16p13.3 & CCNF & ALS-FTD & $\begin{array}{l}<1 \% \text { sALS } \\
0.6-3.3 \% \text { fALS } \\
<4 \% \text { FTD }\end{array}$ & Missense & TDP43 & $\begin{array}{l}\text { Williams et al., 2016; Nguyen } \\
\text { et al., } 2018\end{array}$ \\
\hline $22 q 11.23$ & $\mathrm{CHCHD} 10$ & ALS-FTD & $\begin{array}{l}<1 \% \text { sALS } \\
2 \% \text { fALS }<1 \% \text { FTD }\end{array}$ & Missense/nonsense & TDP43 & $\begin{array}{l}\text { Bannwarth et al., 2014; Nguyen } \\
\text { et al., } 2018\end{array}$ \\
\hline 9p21.2 & C9orf72 & ALS-FTD & $\begin{array}{l}6 \% \text { sALS } \\
37 \% \text { fALS } \\
5 \% \text { sFTD } \\
25 \% \text { fFTD }\end{array}$ & $\mathrm{G}_{4} \mathrm{C}_{2}$ repeat expansion & $\begin{array}{l}\text { TDP43/p62/dipeptides } \\
\text { repeat/ubiquitin }\end{array}$ & $\begin{array}{l}\text { DeJesus-Hernandez et al., } \\
\text { 2011; Renton et al., 2011; } \\
\text { Majounie et al., } 2012\end{array}$ \\
\hline $2 p 13.1$ & DCTN1 & ALS-FTD & $\begin{array}{l}<1 \% \text { sALS } \\
<1 \% \text { fALS }\end{array}$ & Missense & TDP43 & $\begin{array}{l}\text { Puls et al., 2003; Münch et al., } \\
\text { 2004, } 2005\end{array}$ \\
\hline $16 p 11.2$ & FUS & ALS-FTD & $\begin{array}{l}\sim 1 \% \text { sALS } \\
3 \% \text { fALS }<1 \% \text { FTD }\end{array}$ & Missense/nonsense & FUS/p62 & $\begin{array}{l}\text { Kwiatkowski et al., 2009; Vance } \\
\text { et al., 2009; Van Langenhove } \\
\text { et al., } 2012\end{array}$ \\
\hline 10p13 & OPTN & ALS-FTD & $\begin{array}{l}<1 \% \text { ALS } \\
4 \% \text { FTD }\end{array}$ & $\begin{array}{l}\text { Missense/ } \\
\text { deletion/nonsense }\end{array}$ & TDP43/p62 & $\begin{array}{l}\text { Maruyama et al., 2010; Van } \\
\text { Langenhove et al., 2012; } \\
\text { Pottier et al., } 2015\end{array}$ \\
\hline $5 q 35$ & SQSTM1/p62 & ALS-FTD & $\begin{array}{l}2-3 \% \text { ALS } \\
2-3 \% \text { FTD }\end{array}$ & $\begin{array}{l}\text { Missense/nonsense/ } \\
\text { deletion }\end{array}$ & TDP43/p62 & $\begin{array}{l}\text { Fecto and Siddique, 2011; Elisa } \\
\text { et al., 2012; Le Ber et al., } 2013\end{array}$ \\
\hline $12 q 14.2$ & TBK1 & ALS-FTD & $\begin{array}{l}<1 \% \text { sALS } \\
3 \% \text { fALS } \\
<1 \% \text { FTD }\end{array}$ & Missense/nonsense & TDP43/p62 & $\begin{array}{l}\text { Cirulli et al., 2015; Freischmidt } \\
\text { et al., 2015; Nguyen et al., } \\
\text { 2018; Lamb et al., } 2019\end{array}$ \\
\hline 2p13.3 & $\mathrm{TIA} 1$ & ALS-FTD & $\begin{array}{l}<1 \% \text { sALS } \\
2.2 \% \text { fALS } \\
<1 \% \text { FTD }\end{array}$ & Missense & TDP43/p62 & $\begin{array}{l}\text { Mackenzie et al., 2017; Nguyen } \\
\text { et al., } 2018\end{array}$ \\
\hline 2q35 & TUBA4A & ALS-FTD & $\begin{array}{l}<1 \% \text { sALS } \\
1 \% \text { fALS } \\
<1 \% \text { FTD }\end{array}$ & Missense/nonsense & TDP43 & $\begin{array}{l}\text { Smith et al., 2014; Nguyen } \\
\text { et al., } 2018\end{array}$ \\
\hline $9 p 13.3$ & VCP & ALS-FTD & $\begin{array}{l}1-2 \% \text { fALS } \\
<1 \% \text { FTD }\end{array}$ & Missense & TDP43/p62 & $\begin{array}{l}\text { Watts et al., 2004; Johnson } \\
\text { et al., } 2010\end{array}$ \\
\hline Xp11.21 & UBQLN2 & ALS-FTD & $\begin{array}{l}2 \% \text { ALS } \\
<1 \% \text { FTD }\end{array}$ & Missense & $\begin{array}{l}\text { TDP43/p62/ubiquitin/ } \\
\text { FUS/OPTN }\end{array}$ & $\begin{array}{l}\text { Deng et al., 2011; Synofzik } \\
\text { et al., } 2012\end{array}$ \\
\hline $3 p 11.2$ & $\mathrm{CHMP2B}$ & FTD & $\begin{array}{l}<1 \% \text { ALS } \\
<1 \% \text { FTD }\end{array}$ & Missense/nonsense & Ubiquitin/P62 & $\begin{array}{l}\text { Skibinski et al., 2005; } \\
\text { Parkinson et al., 2006; Van } \\
\text { Langenhove et al., } 2012\end{array}$ \\
\hline $17 q 21.31$ & GRN & FTD & $\begin{array}{l}1-5 \% \text { sFTD } \\
5-20 \% \text { fFTD }\end{array}$ & $\begin{array}{l}\text { Missense/nonsense/splice } \\
\text { site/frameshift }\end{array}$ & TDP-43 & $\begin{array}{l}\text { Baker et al., 2006; Cruts et al., } \\
\text { 2006; Rademakers et al., } 2012\end{array}$ \\
\hline $17 q 21.2$ & MAPT & FTD & $5-20 \%$ fFTD & $\begin{array}{l}\text { Missense/splice } \\
\text { site/deletion }\end{array}$ & Tau & $\begin{array}{l}\text { Hutton et al., 1998; } \\
\text { Rademakers et al., } 2012\end{array}$ \\
\hline
\end{tabular}

Characteristics of major genes associated with ALS or FTD. Table is adapted from Hardy and Rogaeva (2014). 


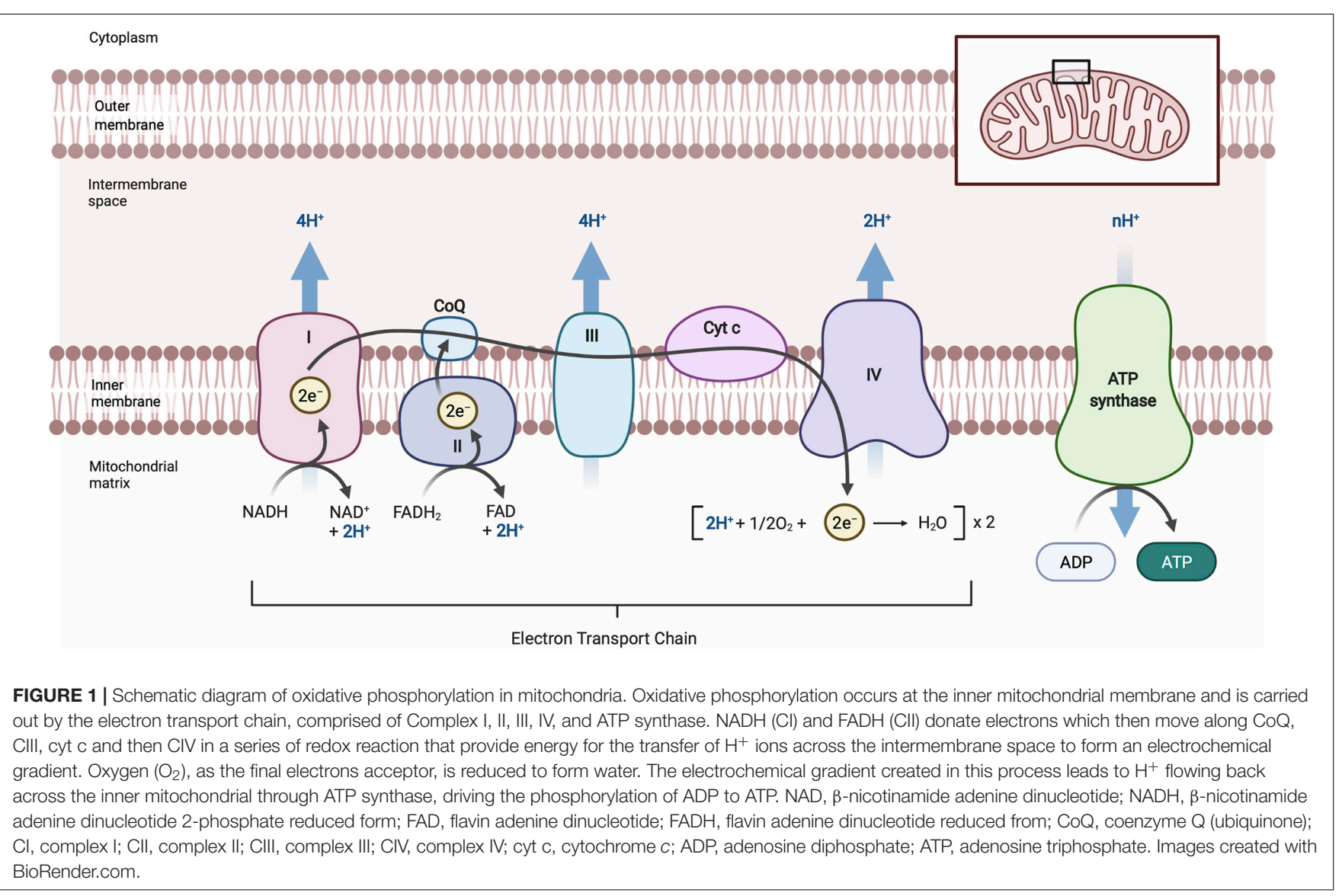

To investigate the roles of mitochondrial dysfunction and other disease mechanisms, both patient-derived cells and animal models have been essential scientific tools (Vandamme, 2014; Roberts and Speirs, 2017; Kim et al., 2020). With the advent of GWAS studies a multitude of mutations have been linked to disease development (Witte, 2010; Tam et al., 2019). Confirming that these mutations cause disease, and understanding how they lead to neurodegeneration, has often required the generation of animal models carrying these mutations. These models have allowed the field to build an initial understanding of how disease-associated mutations lead to declining organismal health generally and neurodegeneration specifically. Among animal models, the fruit fly Drosophila has proven invaluable in modeling neurodegenerative disease. Over 20 years ago, the first fly models of neurodegeneration showed, crucially, that overexpression of human disease genes in flies could not only lead to neurodegeneration (Warrick et al., 1998) but also mimic the main characteristics of the disease (Feany and Bender, 2000). Since then, a host of neurodegenerative disease models have been developed in flies, which have provided critical insights into disease pathology.

The success of flies stems from the fact that flies require little space, have short life cycles with abundant offspring, and are easy and inexpensive to breed and maintain in large numbers (providing strong statistical power) (Ashburner and Bergman, 2005; Figure 2). In this review, we will give a general overview of Drosophila as a model system to study FTD/ALS, with a focus on how Drosophila has been a powerful tool to study mitochondrial dysfunction in models of these diseases.

\section{Drosophila AS A MODEL SYSTEM}

\section{Drosophila Biology}

Since Thomas H. Morgan used Drosophila in his 'Fly Room' at Columbia University to study genetic inheritance in 1910, Drosophila has been widely used as a model organism. Thomas $\mathrm{H}$. Morgan won the Nobel Prize in Physiology or Medicine in 1933 for formulating the chromosomal theory of inheritance, based on his findings looking at patterns of inheritance of the white eye pigment in flies. To date, 6 Nobel Prizes in Physiology or Medicine have been awarded to 10 researchers using flies in their research including Thomas' proteges Allan Sturtevant, Calvin Bridges and Hermann Muller (Zhang K. et al., 2018). These trailblazing studies underscore the fundamental contribution of this unassuming model organism to our current understanding of many aspects of biology.

Drosophila development and physiology are surprisingly similar to those in more complex eukaryotes. For example, Drosophila has a similar dorsoventral patterning to vertebrates with the ventral area of Drosophila being analogous to the dorsal area in vertebrates (De Robertis and Sasai, 1996). Moreover, homologous genes control the patterning of the organism. Among these, decapentaplegic $(d p p)$ is expressed in the dorsal 


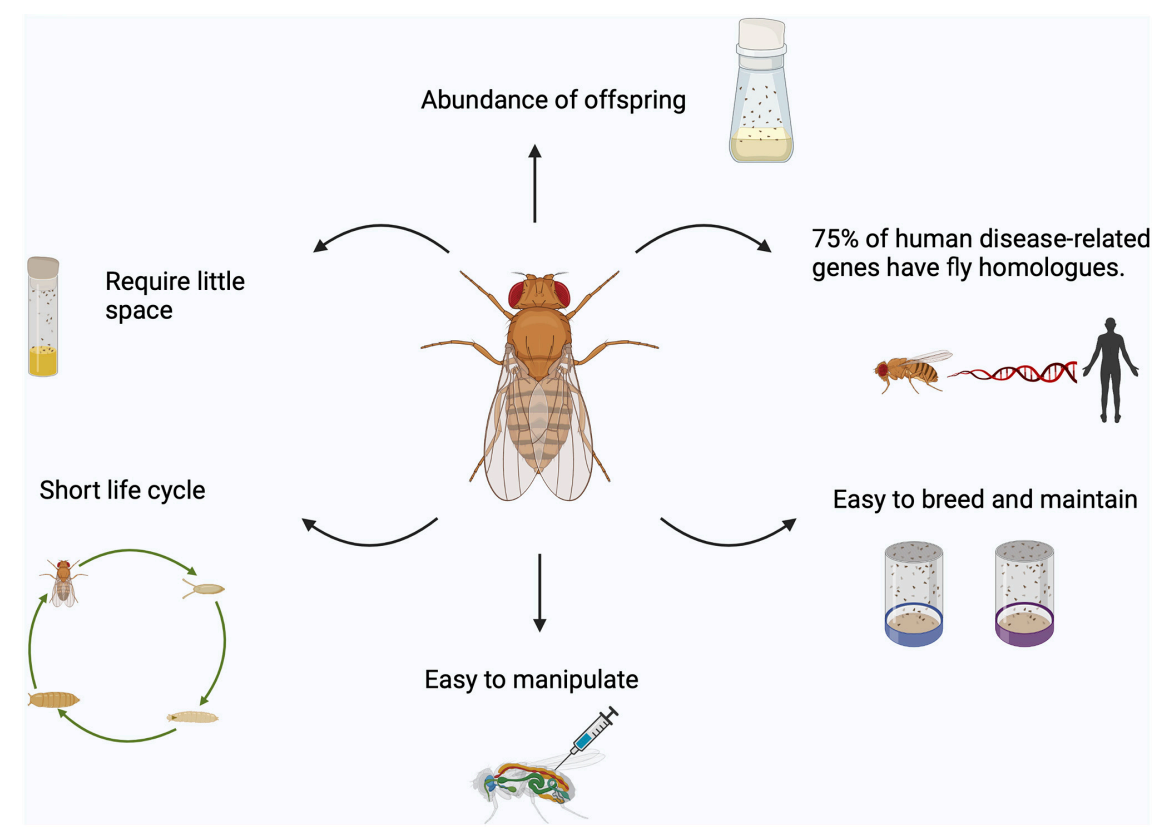

FIGURE 2 | Advantages of using Drosophila as a model organism. Fruit flies are easy to breed and maintain in large numbers, easy to manipulate, require little space, have short life cycle with abundant offspring and about $75 \%$ of human disease-related genes have fly homologs. Images created with BioRender.com.

region of Drosophila, whereas the vertebrate homolog, bone morphogenetic protein $4(b m p-4)$, is expressed in the ventral region. Similarly, short gastrulation (sog) in Drosophila is expressed in the ventral region, whilst it vertebrate homolog, chordin (chordin), is expressed in the dorsal region (Holley et al., 1995). Drosophila also shows strong similarity to vertebrates in organ development: Hedgehog (Hh) in Drosophila, has a similar limb patterning function as Sonic hedgehog $(\mathrm{SHH})$ in vertebrates (Riddle et al., 1993), and Paired Box 6 (Pax6) in both flies and vertebrates has analogous functions in eye development (Wawersik and Maas, 2000). Finally, the components of major signaling pathways, such as Wingless and Notch, are also conserved between flies and vertebrates (Baker, 1987; Fleming, 1998; Bejsovec, 2018). The conservation extends to genes and signaling pathways modulating longevity and aging, a field in which Drosophila has provided fundamental insights (Piper and Partridge, 2018). For instance, the discovery that chico (insulinreceptor substrate) and $\operatorname{In} R$ (insulin-like receptor) mutants extended lifespan in flies (Clancy et al., 2001; Tatar et al., 2001) prompted subsequent studies confirming similar findings in vertebrate models (Selman et al., 2008). Metabolic pathways are also highly conserved between mammals and Drosophila, making flies a valuable model system for metabolism research such as in diabetes and obesity (Baker and Thummel, 2007; Bharucha, 2009).

Flies are also the simplest model organism extensively used in research with a complex body pattern and many organs are analogous to those in humans. For example, flies have a gut, a beating heart, and a clearly defined central and peripheral nervous systems, allowing them to model multisystem phenotypes associated with disease mutations. These features have enabled Drosophila to provide numerous insights in the study of complex human diseases such as cancer, cardiovascular diseases, and neurodegenerative diseases. For instance, Drosophila has been used to identify and screen drugs for cancer therapeutics (Hirth, 2010; Bangi et al., 2019), and to study embryonic cardiac development and adult cardiac performance (Piazza and Wessells, 2011).

Drosophila has also been used extensively to study neurodegenerative diseases. Although the Drosophila brain is not as anatomically complex as the mammalian one, the cellular and molecular characteristics of the nervous system are broadly similar. At the cellular level, Drosophila and mammalian nervous systems both possess functionally distinct categories of neuronal and glial cells, and both possess a blood brain barrier (Stork et al., 2012; Kasture et al., 2018). Flies also display a range of complex behaviors such as sleep, learning and memory, courtship, and navigation. Importantly, these behaviors decline with age and in the presence of toxic genes associated with disease in humans, making flies a useful tool to study neurodegenerative diseases (Buchanan and Benzer, 1993; Jackson et al., 1998; Warrick et al., 1998).

At the genome level, Drosophila is simpler than vertebrate models, with only 4 chromosomes and 13,821 genes. However, the completed sequencing of the Drosophila genome has shown that about three-quarter of human disease-related genes have homologs in Drosophila (Reiter et al., 2001). Moreover, the Drosophila genome has relatively low genetic redundancy: classes of genes with multiple members in humans are often represented by only a single orthologous gene in flies. Drosophila research also benefits from its own comprehensive, easily searchable, database, known as FlyBase, where all published information 
about flies is cataloged soon after publication. This impressive repository provides researchers with access to a wide range of information, allowing them to coordinate their studies more efficiently. Because Drosophila as a model organism has been studied for over 100 years, the field has also developed a vast array of tools for manipulating and monitoring gene expression, placing Drosophila at the forefront of large-scale genetics screens. Classical X-ray radiation exposure, feeding with the mutagen ethyl methane sulfonate (EMS) (Greenspan, 1997), and the development of transposable P-element insertions have helped produce massive mutant strain collections which can be used to investigate different biological processes. Large collections of Drosophila strains have also been generated for over-expression of genes of interest (EP lines and FlyORF lines), as well as for RNAi-mediated down regulation of endogenous genes (Trip and VDRC RNAi lines) (Bellen et al., 2004; Dietzl et al., 2007; Bischof et al., 2013; Perkins et al., 2015) (Additional information about Drosophila stocks, reagents, online tools and key resources are reviewed extensively in Mohr et al., 2014). The presence of these large collections dramatically speeds up research by saving individual researchers the time and effort of designing and developing new lines. Moreover, the cell-type-specific effects of gene overexpression or knockdown can be studied using bipartite expression systems such as GAL4/UAS (upstream activating sequence) (Brand and Perrimon, 1993).

The GAL4/UAS bipartite system is an extensively used tool for controlling gene expression in flies (Brand and Perrimon, 1993). It takes advantage of the yeast transcriptional activator GAL4, which is usually cloned downstream of a tissue specific enhancer (conferring a determined expression pattern). GAL4 binds to UAS, activating the transcription of the gene of interest cloned downstream of it, in a spatiotemporal manner matching the GAL4 expression pattern (Fischer et al., 1988; Brand and Perrimon, 1993). The fly line containing the GAL4 is often called the 'driver', and the transgene fly line that carries the UAS is often called the 'responder' or 'reporter.' The two elements are kept as separate fly stocks so that the expression of the UAS line is only induced in the progeny of crosses between driver and responder lines (Figure 3). There are currently nearly 8000 GAL4 and derivative lines, offering an ever increasingly precise toolkit for cell-type-specific expression of transgenes ${ }^{1}$. Importantly, most of these lines are available from public repositories. In particular, there are a plethora of GAL4 lines for different brain cell types (Pfeiffer et al., 2008; Jenett et al., 2012), allowing studies of very specific neuronal or glial sub-populations (see Doherty et al., 2009; Luan et al., 2020).

Subsequent refinements to this system have also improved temporal control: the temperature-sensitive GAL80 protein suppresses the GAL4 activity at lower temperatures $\left(16^{\circ} \mathrm{C}\right)$ but is inactivated at higher temperatures $\left(29^{\circ} \mathrm{C}\right)$, allowing genes to be turned on via a temperature shift (Lue et al., 1987; Duffy, 2002). More recently, Gal4-Geneswitch has been developed, where the GAL4 DNA binding domain has been fused to a progesterone inducible element which is activated upon feeding of the drug RU486 (Osterwalder et al., 2001; Nicholson et al., 2008). This

${ }^{1}$ https://bdsc.indiana.edu/stocks/gal4/index.html system has been extensively used in neurodegenerative disease models to restrict expression of toxic constructs exclusively to adult neurons, a particularly useful feature for modeling diseases of adulthood as it avoids any confounding developmental effects (Sofola et al., 2010).

The ease of access to large libraries of stocks has enabled numerous large-scale enhancer and suppressor screens. This type of screen has been extensively used in neurodegenerative disease models to help identify downstream pathways of toxicity (Bilen and Bonini, 2007; Butzlaff et al., 2015; Zhang et al., 2015; Belfiori-Carrasco et al., 2017). The aim of these screens has been to identify factors that worsen (enhance) or ameliorate (suppress) the phenotype associated with a particular disease model. One of the most easily and commonly screened characteristics in Drosophila is the compound eye. Drosophila eyes are ideally suited as a genetic screening tool for diverse biological process, since about two-thirds of essential genes in Drosophila are involved in eye development (Thaker and Kankel, 1992). Furthermore, the complexity of the Drosophila eye, which encompasses 800 ommatidia, each in turn containing 8 photoreceptors, means that quantifiable features such as the number of ommatidia affected can precisely reflect the severity of the phenotype (Bate and Arias, 1993; St Johnston, 2002). At a macroscopic level, the size and roughness of the eye can also provide an immediate, scorable measure of cell death, which can be used as a rapid phenotypic readout. This serves as an ideal tool to conduct high throughput and unbiased screens (Lenz et al., 2013). Other screenable phenotypes linked to neurodegeneration include climbing ability, viability, and lifespan. Importantly, screens in flies have highlighted a number of pathways involved in disease development which have later been shown to be conserved in mammalian systems (reviewed in McGurk et al., 2015).

\section{Drosophila Mitochondrial Biology}

Unsurprisingly given their central role in eukaryotic biology, Drosophila and human mitochondria show a very high degree of conservation in both genetic architecture and biochemical pathways. At the genomic level, Drosophila mitochondrial DNA (mtDNA) has similar components to human mtDNA, although the human mtDNA genome is $16,559 \mathrm{bp}, 3 \mathrm{~kb}$ shorter than the Drosophila mtDNA genome at 19,517 bp (Lewis et al., 1995). Human mtDNA contains 13 polypeptides, 22 tRNAs and 2 rRNAs encoding the same components as Drosophila mtDNA, albeit with a slightly different genomic order (Garesse and Kaguni, 2005). The molecular functions typically associated with mitochondria, such as OXPHOS, mitochondria transport, and biogenesis are highly conserved, as are the nuclear-encoded genes required for mitochondrial function (Chen et al., 2019). Drosophila has therefore been an excellent model system to study mitochondrial function, with relevance to mitochondrial biology broadly and to neurodegeneration specifically.

One of the earliest examples of using Drosophila to study mitochondrial biology was the characterization of phenotypes in flies mutant for the technical knockout ( $t k o$ ) gene (Royden et al., 1987). Tko is the nuclear-encoded mitochondrial ribosomal protein S12 (mRpS12) (Mariottini et al., 1999). The $t k o^{25 t}$ 


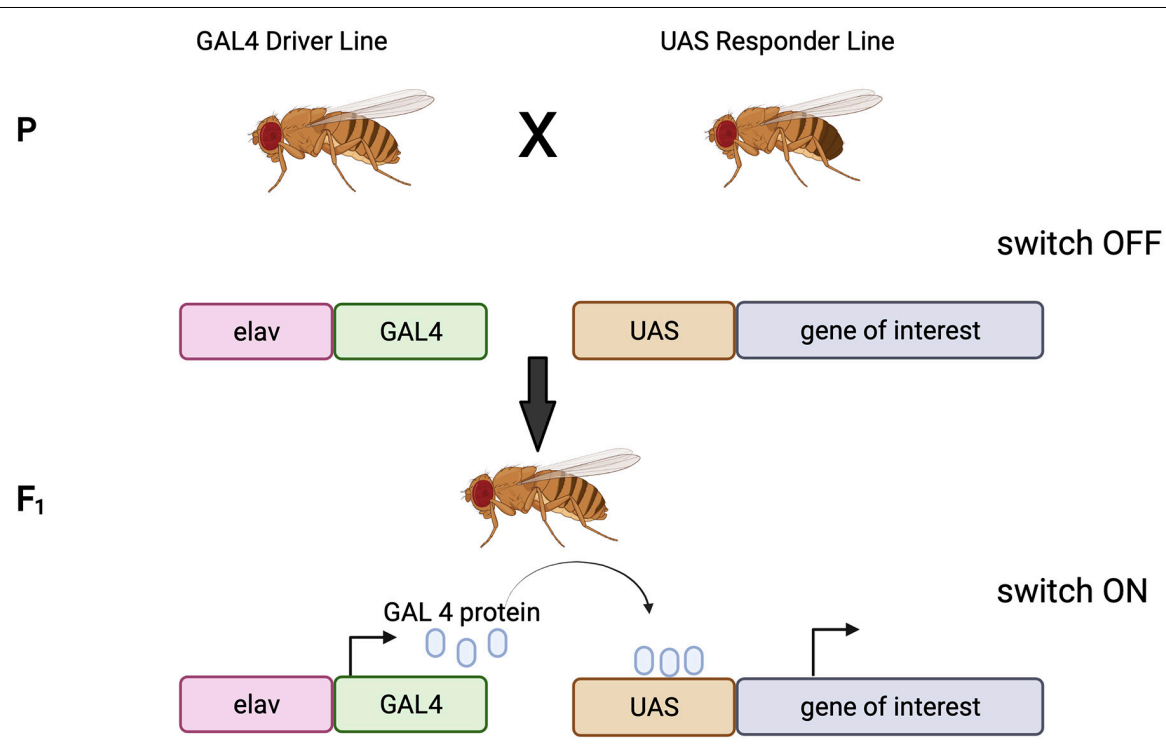

FIGURE 3 | GAL4/UAS bipartite system of expression. The driver line contains a tissue specific promoter (in this case the neuronal specific elav promoter), driving the expression of yeast GAL4 protein in neurons. The responder line carries the gene of interest cloned down-stream of the UAS promoter, this, however, is not expressed. When the driver line is crossed to the responder line, the GAL4 driver and the UAS-transgene construct will come together in one animal. The GAL4 will be expressed in neurons, bind the UAS promoter and drive the expression of the gene of interest specifically in neurons. Images created with BioRender.com.

mutant has reduced complex I, II, and IV activity and reduced ATP synthesis (Toivonen et al., 2001). This disruption in the electron transport chain (ETC) leads to a number of observable phenotypes, including seizure sensitivity, larval developmental delay, hearing impairments, and defective male courtship (Toivonen et al., 2001). Remarkably, these behavioral defects resemble the key features in patients with such disorders (Jacobs et al., 2004), providing early evidence that fly models could be used to model human mitochondrial disease. Indeed, several mitochondrial diseases models have since been developed which emulate the physiological symptoms seen in patients with mitochondrial disorders (Jacobs et al., 2004; Xu et al., 2008; Fernández-Ayala et al., 2010). Beyond mitochondrial diseases specifically, Drosophila tko mutants have been used in epilepsy research as the tko bang sensitive (bs) paralytics mutant displays similar features to those seen in human seizure disorders (Song and Tanouye, 2008; Whelan et al., 2010).

Drosophila models have also proved useful in defining the phenotypes most affected by defective mitochondria. For example, Drosophila studies defined mitochondria's key role in sperm development and male fertility. Fuzzy onions (fzo), the founding member of the Mitofusin (Mfn) family of proteins, was first characterized in flies. Mutant fzol mitochondria are unable to fuse in early spermatocytes, disrupting mitochondria organization and leading to male sterility (Hales and Fuller, 1997). Notably, these phenotypes have been replicated in mammalian models and observed in human patients (Zhang et al., 2016).

Finally, fly models have also proved invaluable to understanding the role of mitochondria in neurodegenerative disorders. For example, following the identification of mutations in PINK1, a PTEN-induced serine/threonine kinase 1, and in the
E3 ubiquitin ligase Parkin, as causative genes in monogenic PD, flies were instrumental in identifying the role of these genes in mitochondrial biology (Clark et al., 2006; Park et al., 2006; Deng et al., 2008; Poole et al., 2008; Yang et al., 2008). Flies were used to show that both PINK and Parkin were implicated in the same biological pathway, playing a fundamental role in mitochondrial dynamics and degradation of dysfunctional mitochondria via mitophagy (Clark et al., 2006; Park et al., 2006; Deng et al., 2008; Poole et al., 2008; Yang et al., 2008).

\section{Assays for Studying Mitochondrial Biology}

The study of mitochondria in flies is bolstered by a large number of assays to characterize mitochondrial form and function in detail, both in live and fixed tissue of wildtype and mutant Drosophila (Sen and Cox, 2017).

A number of general purpose dyes have been developed to visualize mitochondria; nearly all of these can be used in Drosophila tissues. The cell-permeant mitochondrion-selective dye MitoTracker Green has been used to observe mitochondrial mass (Rana et al., 2017). Specifically, MitoTracker Green labels the mitochondria matrix by covalently binding free thiol groups on cysteine residues belonging to mitochondrial proteins (Presley et al., 2003). A number of dyes have also been developed to measure mitochondrial membrane potential (MMP), a parameter that correlates with the mitochondrial ability to generate ATP. Tetramethylrhodamine, methyl ester (TMRM) or Tetramethylrhodamine, ethyl ester (TMRE), and 5,5', 6,6'-tetrachloro-1,1',3,3' -tetraethyl-benzimidazolylcarbocyanine iodide (JC1) dyes are some of the most commonly used dyes used for this purpose. TMRM, TMRE, and JC-1 are all fluorescent 
TABLE 2 | Genetically encoded mitochondrial biosensors/tools developed in Drosophila.

\begin{tabular}{|c|c|c|c|}
\hline Sensor line & Sensor type & Brief description & References \\
\hline $\begin{array}{l}\text { UAS-AT1.03NL/ } \\
\text { UAS-AT1.03RK }\end{array}$ & ATP sensor & $\begin{array}{l}\text { FRET sensor for live imaging, consisting of an ATP binding sequence located } \\
\text { between two fluorophores. Upon ATP binding the two are brought in close } \\
\text { proximity leading to increased FRET signal. }\end{array}$ & Tsuyama et al., 2013 \\
\hline $\begin{array}{l}\text { UAS-mitoGFP } \\
\text { UAS-mitoDSRed }\end{array}$ & Mitochondrial marker & $\begin{array}{l}\text { Green or Red fluorescent protein tagged with a mitochondrial import sequence } \\
\text { (acting as targeting signal to the mitochondrial matrix), used to visualize all } \\
\text { mitochondria in live or fixed tissue. }\end{array}$ & $\begin{array}{l}\text { Lutas et al., 2012; DeVorkin } \\
\text { et al., 2014; Chowdhary et al., } \\
\text { 2017; Morris et al., } 2020\end{array}$ \\
\hline UAS- mito-GCaMP3 & Ca2 + sensor & $\begin{array}{l}\text { Circularly permutated EGFP M13/Calmodulin fusion protein, tagged with a } \\
\text { mitochondrial import sequence. Upon Ca2 + binding the construct undergoes } \\
\text { a conformational change, increasing fluorophore output, thus allowing to } \\
\text { monitor } \mathrm{Ca} 2+\text { concentration in live cells. }\end{array}$ & $\begin{array}{l}\text { Lutas et al., 2012; Morris et al., } \\
2020\end{array}$ \\
\hline UAS-PercevalHR & ATP/ADP sensor & $\begin{array}{l}\text { Fluorescent biosensor composed of three tandem copies of an ATP-binding } \\
\text { protein fused to a circularly permuted monomeric Venus. It has a dual excitation } \\
\text { spectrum, with a peak at } 405 \mathrm{~nm} \text {, enhanced by ATP binding and at } 488 \mathrm{~nm} \text {, } \\
\text { enhanced by ADP binding. The ratiometric signal reports the occupancy and } \\
\text { therefore ATP/ADP ration in live cells. }\end{array}$ & $\begin{array}{l}\text { Morris et al., 2020; Wong et al., } \\
2021\end{array}$ \\
\hline UAS-SoNaR & $\mathrm{NADH} / \mathrm{NAD}+$ sensor & $\begin{array}{l}\text { Fluorescent biosensor composed of a fusion of circularly permuted yellow } \\
\text { fluorescent protein and an NADH-binding domain. It binds to NAD and NADH } \\
\text { with two specific conformation, associated with a different excitation spectrum. } \\
\text { The ratiometric signal reports the occupancy and therefore NADH/NAD + ratio } \\
\text { in live cells. }\end{array}$ & $\begin{array}{l}\text { Bonnay et al., 2020; Morris } \\
\text { et al., } 2020\end{array}$ \\
\hline $\begin{array}{l}\text { UAS-mito-roGFP2-Grx1/ } \\
\text { UAS-mito-roGFP2-Orp1 }\end{array}$ & REDOX sensors & $\begin{array}{l}\text { Mitochondrially targeted, redox sensitive GFPs, with a dithiol/disulfide switch on } \\
\text { their surface leading to measurable ratiometric fluorescent change in response } \\
\text { to redox changes in live mitochondria. These are fused to glutaredoxin (Grx), } \\
\text { which increases specificity for glutathione or a microbial Orp1 } \mathrm{H}_{2} \mathrm{O}_{2} \text { sensor, } \\
\text { making it specific for } \mathrm{H}_{2} \mathrm{O}_{2} \text {. }\end{array}$ & $\begin{array}{l}\text { Albrecht et al., 2011; Morris } \\
\text { et al., } 2020\end{array}$ \\
\hline UAS-Dendra2.mito & $\begin{array}{l}\text { Photoconvertible } \\
\text { mitochondrial tag }\end{array}$ & $\begin{array}{l}\text { Mitochondrially localized photoconvertible protein that can be irreversibly } \\
\text { photoconverted from a green fluorescent form to a red fluorescent form, by } \\
\text { UV-violet or blue light. It allows to monitor behavior of photoconverted } \\
\text { mitochondria over time. }\end{array}$ & $\begin{array}{l}\text { Hwang et al., 2014; Bertolin } \\
\text { et al., } 2018\end{array}$ \\
\hline UAS-mito-PyronicSF & Pyruvate sensor & $\begin{array}{l}\text { Mitochondrially targeted pyruvate FRET sensor composed of a circularly } \\
\text { permuted GFP fused to a bacterial pyruvate sensitive transcription factor. Upon } \\
\text { pyruvate binding a conformational change leads to increased FRET signal. }\end{array}$ & Arce-Molina et al., 2020 \\
\hline
\end{tabular}

cationic dyes that accumulate in mitochondria based on their potential, the more polarized mitochondria are, the more the dyes accumulate. For TMRM and TMRE this results in a brighter signal at high MMP (Perry et al., 2011). JC1, on the other hand, changes color according to its concentration, forming red aggregates at high concentrations in healthy mitochondria, and remaining as a green monomer in mitochondria with low MMP (Sivandzade et al., 2019). The MMP in this case is measured by the ratio of the red/green fluorescence intensity. Finally, MitoSOX dye can be applied to measure ROS production (Yarosh et al., 2008). This fluorescent cationic dye is a derivative of dihydroethidum; in the presence of superoxide, MitoSOX is selectively oxidized in the mitochondrial matrix of live cells, where it emits a red color (Roelofs et al., 2015).

In addition to dyes, a host of fluorescent genetically encoded probes and bio-sensors have also been developed, particularly in Drosophila. As the genes encoding these sensors are usually under the control of the UAS promoter, they can be driven by cell-type specific GAL4 drivers. This allows monitoring of mitochondria morphology, physiology, and key metabolites in vivo in specific cell populations (Table 2).

Drosophila has also been a useful model system for developing tools to assess specific molecular products of mitochondrial activity. For example, the MitoB probe, which uses a ratiometric mass spectrometry approach to measure $\mathrm{H}_{2} \mathrm{O}_{2}$ in the mitochondrial matrix, was developed using Drosophila (Cochemé et al., 2011). The probe contains a triphenylphosphonium (TPP) cation which is then conjugated to an arylboronic acid target in the mitochondria matrix; the final product is then measured by liquid chromatography tandem mass spectrometry.

Another important assay to study mitochondrial physiology is the measurement of oxygen consumption, which is directly linked to OXPHOS activity as the final step of the ETC involves the reduction of oxygen to water. One assay for measuring oxygen consumption is the high-resolution Oxygraph-2k, also called Oroboros, which measures oxygen consumption as well as additional parameters such as ROS production, mitochondrial membrane potential, ATP production, $\mathrm{Ca}^{2+}$, and $\mathrm{pH}^{2}$. Oroboros measures oxygen uptake and concentration after the injection of substrates for different ETC components, directly to samples immersed in a specific solution within a detection chamber. It requires a small amount of sample, with only 2 flies being sufficient for an assay (Costa et al., 2013). Advantages of this system include its flexibility to study each complex individually and its ability to perform serial measurements in the same sample,

\footnotetext{
${ }^{2}$ https://www.oroboros.at/index.php/o2k-concept/
} 
and its relatively low cost (Perry et al., 2013). Nonetheless, this system is relatively slow and low throughput.

The Seahorse XF Extracellular Flux Analyzer (Seahorse Bioscience Inc.) was introduced more recently to enable high throughput testing, albeit at extra cost. The instrument can measure the rate of mitochondrial OXPHOS (through determination of the oxygen consumption rate) and glycolysis through extracellular acidification rate (ECAR). The system achieves higher throughput by using fluorescent sensor cartridges on 24 or 96 cell-culture microplates. In addition, the microplate-based assay has 4 ports to inject substrates and/or inhibitors to assess multiple conditions consecutively (reviewed in Horan et al., 2012).

Finally, a number of spectrophotometric assays have also been developed to study the activity of mitochondrial enzymes or the concentration of individual metabolites. These assays possess the advantage of being relatively cheap, rapid and reliable (BirchMachin and Turnbull, 2001; Barrientos, 2002; Barrientos et al., 2009). They provide information on the catalytic activities of each respiratory chain complex or combination of complexes by following the production or depletion of particular substrates which absorb or transmit light at specific wavelengths. The results are then usually standardized against citrate synthase activity, frequently used as a standard in mitochondria (Frazier and Thorburn, 2012). The downsides of these assays are that few samples can be measured at one time, and they generally require a relatively large quantity of sample (Janssen and Boyle, 2019).

\section{Assays to Assess Health and Behavior in Drosophila}

As described earlier, mitochondrial defects in flies have physiological implications on the whole organism that result in alterations in behavior and lifespan. These can provide useful organism-level phenotypic readouts of mitochondrial defects. Lifespans is one of the most commonly used readouts for late onset phenotypes in flies. Because of the sensitivity of lifespan as an assay, thorough protocols have been developed to standardize the many factors that can influence lifespan (Piper and Partridge, 2016). The healthy lifespan of flies can be evaluated across 'normal' aging, or lifespan can be assessed in the presence of mitochondrial stressors such as paraquat or rotenone to investigate the flies' sensitivity to oxidative stress (Menzies et al., 2005; Meulener et al., 2005).

In addition to shortened lifespan, impairments in mitochondrial function can lead to more subtle neurological defects and neurodegeneration in flies, as well as in humans. A large number of assays have been developed to monitor neuronal impairments in flies. For instance, 'bang-sensitivity' measures the time for flies to recover from paralysis after being strongly shaken to the base of a tube. It mimics epilepsy and seizures associated with mitochondrial disease, features found for example in mitochondrial encephalomyopathy with lactic acidosis and stroke-like episodes (MELAS) (Jacobs et al., 2004; Celotto et al., 2006; Burman et al., 2014). In addition, locomotor

\footnotetext{
${ }^{3} \mathrm{https} / / /$ www.agilent.com/en/products/cell-analysis/how-seahorse-xf-analyzerswork
}

dysfunction can be measured in flies via a climbing or negative geotaxis assay, which quantifies the negative geotactic reflex of flies. When gently tapped to the bottom of a chamber, flies naturally climb upwards against gravity and toward light. Flies are allowed to climb for defined time, and the height climbed is scored as an easy parameter that correlates with general locomotor function (Benzer, 1967; Inagaki et al., 2010). The climbing assay is widely used in Drosophila neurodegenerative disease research as it is a rapid readout of neuromuscular function, albeit a readout that lacks information on the exact tissues and circuits involved in any observed deficits.

Locomotion, sleep, and circadian rhythms can also be monitored with the widely used Drosophila activity monitoring (DAM) system (Pfeiffenberger et al., 2010). Flies are placed in sealed tubes with food within a climate and light-controlled incubator; monitors then use infrared beams to record each time a fly walks past a defined point within the tube (an event). Events are continuously scored for 3-4 days to monitor activity. To study sleep, a significant body of Drosophila sleep research has come to the consensus that 'sleep' can be defined in the DAM system as zero events for a sustained period of $5 \mathrm{~min}$ or more (Beckwith and French, 2019). The DAM system can therefore easily record movement and sleep. Circadian rhythmicity can also be assessed by transitioning the flies to constant darkness and observing how strongly and with what period circadian activity cycles persist. All of these parameters are influenced by neuronal health, in flies as well as humans, and can be used as sensitive measures for the effects of mitochondrial mutations on brain health.

\section{EVIDENCE OF MITOCHONDRIAL DYSFUNCTION IN FRONTOTEMPORAL DEMENTIA AND AMYOTROPHIC LATERAL SCLEROSIS}

The roles of mitochondria in FTD/ALS development have been underscored by the identification of disease mutations in the gene encoding the mitochondrial $\mathrm{CHCHD} 10$ protein. CHCHD10 localizes to the mitochondrial intermembrane space and is enriched at cristae junctions. Although the precise role of $\mathrm{CHCHD} 10$ is still unclear, muscle biopsies and fibroblasts from patients exhibit mitochondrial morphology defects, disorganization of cristae, and respiratory chain deficiencies such as abnormal complex $\mathrm{V}$ assembly (Bannwarth et al., 2014). CHCHD10 mutations also affect the stability of mitochondrial DNA in skeletal muscle (Bannwarth et al., 2014). Disease associated mutations can lead to impaired CHCHD10 mitochondrial import (Lehmer et al., 2018), and model systems suggest the R15L and S59L variants can display loss of function and dominant negative phenotypes, leading to mitochondria damage, accumulation of cytoplasmic TDP-43, and consequent synaptic dysfunction (Woo et al., 2017).

Other mutations linked to FTD/ALS have also been described to affect mitochondria in multiple ways, suggesting potentially a common pathogenic mechanism downstream of 
multiple causal mutations. We outline briefly below some of the major mitochondrial defects associated with FTD/ALS disease variants; for a more comprehensive discussion please see Smith et al. (2019).

\section{Mitochondrial Morphology/Dynamics}

Mitochondria are a highly dynamic organelles that can change shape through fission/fusion events. When mitochondrial dynamics are disrupted, mitochondrial morphology and distribution are disrupted, which impinges directly on mitochondrial function. In ALS and in disease models, a number of studies have found aberrant mitochondrial morphology. For instance, post-mortem studies of tissue from sporadic ALS patients show swollen and mis-shapen mitochondria in the spinal cord (Sasaki and Iwata, 2007). A number of transgenic models with SOD1 mutations also display aberrant dynamics and morphology: for example, SOD1 G93A SH-SY5Y and NSC-34 cell lines show disrupted mitochondrial dynamics with the fission protein dynamin-related protein (Drp1) level increased and optic atrophy 1 (Opa1), a mitochondrial fusion protein, decreased (Ferri et al., 2010). Similarly in SOD1 G93A transgenic mouse spinal cord, Drp1 and mitochondrial Fission 1 (Fis 1) proteins are increased, while levels of the fusion proteins Mfn1 and Opal are reduced (Liu et al., 2013). This is also recapitulated in transgenic mice over-expressing mutant SOD1 which display mitochondrial vacuolar degeneration (Kong and $\mathrm{Xu}, 1998$; Jaarsma et al., 2001; Sasaki et al., 2004).

Studies focused on TDP-43 have also identified roles for this disease-associated protein in mitochondrial biology. In primary mouse neurons, overexpression of either wildtype or mutant TDP-43 decreases mitochondrial length and density in neurites; knock-down of TDP-43 exerts the opposite effect (Wang et al., 2013). Similarly, in fibroblasts derived from patients with mutations in TDP43, the mitochondria appear fragmented (Onesto et al., 2016), and EM analyses of TDP43 patient samples reveal cristae morphological defects (Wang et al., 2019).

Hexanucleotide repeat expansions in the C9orf72 gene (Figure 4), the most common genetic cause of both FTD and ALS, also appear to cause mitochondrial deficits based on recent studies. Recent studies in a mouse model expressing one of the products of the $\mathrm{C} 9$ repeats, the dipeptide repeat protein GR, found age dependant inner mitochondria impairment and loss of cristae formation in the prefrontal cortex (Choi et al., 2019). Mitochondria in primary cortical neurons isolated from mice expressing $80 \mathrm{GR}$ repeats, are also shorter in length and less motile compared to mitochondria in wildtype neurons. At the same time, the mitochondrial network in C9 patient derived fibroblasts did not appear substantially fragmented (Onesto et al., 2016). These differences are potentially due to the different cell types, as neurons may be particularly sensitive to mitochondrial dysfunction as discussed above. In addition to morphological differences, mitochondrial dynamics appear to be disturbed in some C9orf72 models. In a C9 mouse model expressing the dipeptide repeat GR, Drp1 levels are increased and Opa1 levels are decreased, similar to the findings from SOD1 mouse models (Choi et al.,

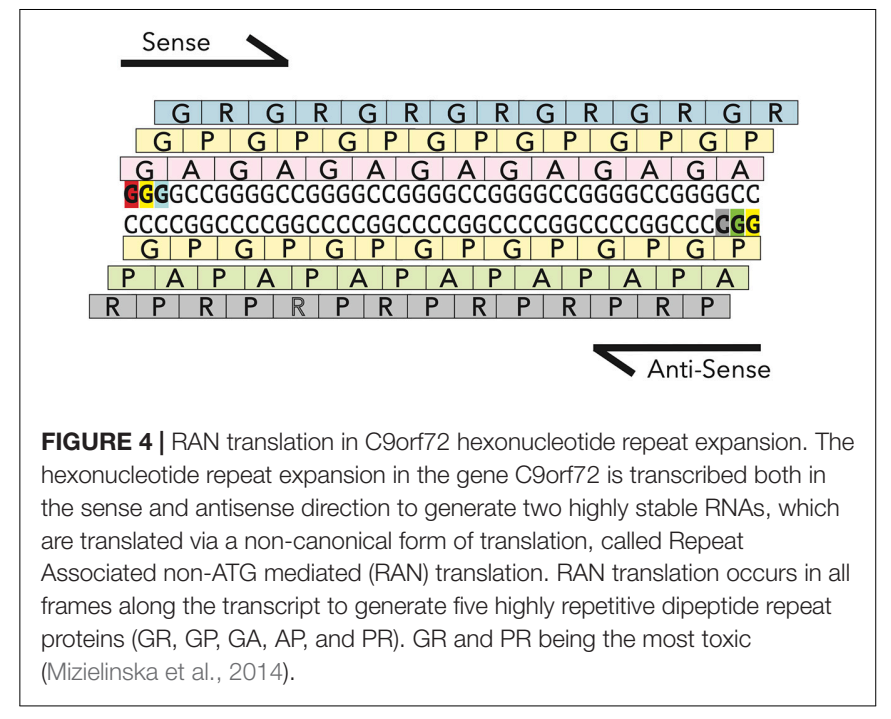

2019). Additionally, induced pluripotent stem cells (iPSC)derived motor neurons with a C9orf72 expansion show impairments in fast axonal transport of mitochondrial cargo (Mehta et al., 2021).

Fused in sarcoma, a gene in which mutations are associated with both FTLD and ALS, provides yet another example of a disease gene associated with mitochondrial deficits. EM analysis has shown morphological abnormalities in mitochondria from FUS patient spinal cord (Huang et al., 2010) and FTLD-FUS patient brain samples (Deng et al., 2015). In cultured neurons, expression of ALS-associated FUS mutants also leads to shortened mitochondria (Tradewell et al., 2012) and mitochondrial fragmentation (Deng et al., 2015, 2018).

\section{Calcium Homeostasis}

Mitochondria play a central role in $\mathrm{Ca}^{2+}$ homeostasis as they store calcium for cell signaling activities and neurotransmitter release. Notably, disturbed mitochondrial calcium homeostasis may be a particularly early marker of pathogenesis in FTD/ALS. For instance, brain and spinal cord samples from mice expressing G93A or G85R mutant SOD1 demonstrate a reduction of calcium-loading capacity in mitochondria very early in the disease course, long before observable symptom onset (Damiano et al., 2006).

Key to the ability of mitochondria to manage $\mathrm{Ca}^{2+}$ levels is their interaction with the endoplasmic reticulum (ER), the other main $\mathrm{Ca}^{2+}$ store. ER-mitochondria contact sites (or MAMs) regulate $\mathrm{Ca} 2$ + exchange between the two organelles (Romero-Garcia and Prado-Garcia, 2019) and are instrumental in maintaining appropriate intracellular $\mathrm{Ca}^{2+}$ homeostasis. As with other mitochondrial phenotypes, MAMs are disrupted in several models of FTD/ALS associated mutations. Expression of either wildtype or mutant TDP-43 or FUS in human and mouse cells disrupts MAMs by disrupting the interaction of two key mediators of ER-mitochondrial interaction: resident ER protein; VAPB and the mitochondrial protein tyrosine phosphatase-interacting protein 51 (PTPIP51) 
(Stoica et al., 2014). C9orf72 hexanucleotide expansions also affect $\mathrm{Ca}^{2+}$ homeostasis. An extensive characterization of iPSC derived motor neurons from patients with C9orf72 expansions showed dysfunction in $\mathrm{Ca}^{2+}$ homeostasis, reduced levels of the antiapoptotic protein $\mathrm{Bcl}-2$, increased ER stress, and reduced mitochondrial membrane potential, resulting in decreased cell survival (Dafinca et al., 2016). This suggests that a disruption of $\mathrm{Ca}^{2+}$ homeostasis is a common phenotype across multiple causal mutations.

\section{Reactive Oxygen Species}

Excessive accumulation of ROS in cells can lead to cell damage and, eventually, cell death (Pizzino et al., 2017). Low levels of ROS perform essential signaling functions (Schieber and Chandel, 2014); however, excess ROS production leads to lipid peroxidation and oxidation of proteins and DNA. ROS are primarily generated in mitochondria as a by-product of oxygen and energy metabolism, making mitochondria a primary target of ROS damage. Excess ROS leads to nitration of mitochondrial proteins, mtDNA damage and mitochondrial respiratory chain dysfunction (Guo et al., 2013).

ALS and FTD, like many other neurodegenerative disorders, have been linked to excessive ROS production and consequent cellular damage. ROS has long been thought to be causally linked to ALS development as the first causal mutations linked to familial ALS were identified in SOD1, a superoxide scavenging enzyme localized to mitochondria whose primary role is to reduce ROS levels. ALS-associated mutations in SOD1 have been associated with increased ROS, with transgenic mice expressing G93A mutant human SOD1 showing oxidative damage to mitochondrial proteins and lipids (Mattiazzi et al., 2002; Vargas et al., 2011; Xiao et al., 2018; Chen et al., 2021; Méndez-López et al., 2021). In cell models as well, expression of G93A SOD1 leads to elevated ROS levels (Liu et al., 2002; Rizzardini et al., 2005) and increased lipid peroxidation level (Liu et al., 2002). Additionally, post mortem tissue from both carriers of SOD1 mutations and sporadic ALS patients display increased ROSassociated damage markers (Beal et al., 1997; Ferrante et al., 1997; Shibata et al., 2001).

Mutations in TDP43 and CHMP2B may also lead to excess ROS production by mitochondria. TDP-43 has been found to localize to mitochondria (Wang et al., 2016, 2019; Yu et al., 2020), and expression of mutant TDP-43 in fly neurons and mammalian cells lead to ROS over-production (Wang et al., 2019). Neurons with mis-localized TDP-43 showed increased ROS production relative to neurons with normal nuclear localization of TDP-43 (Wang et al., 2013). Neurons derived from FTD patients with CHMP2B mutations also show impaired cristae morphology, reduced mitochondrial respiration and increased accumulation of ROS relatively to healthy control neurons (Zhang et al., 2017).

C9 expansions can also lead to excessive ROS production in mitochondria. Motor neurons and fibroblasts derived from patients with expansions in C9orf72 show an age dependant increase in ROS production (Lopez-Gonzalez et al., 2016; Onesto et al., 2016). In fibroblasts, this is accompanied by an increase in oxygen consumption, ATP production and mitochondria hyperpolarization, possibly linked to an increase in mitochondrial biogenesis (Onesto et al., 2016). The mitochondrial dysfunction is potentially due to the highly positively charged GR, one of the repetitive dipeptides produced by the C9orf72 expansion. GR80 expressed in motor neurons has been observed to bind mitochondrial ribosomal proteins, leading to increased ROS production level and increased DNA damage; this is not the case with GA80, another C9-produced but uncharged repetitive protein (Lopez-Gonzalez et al., 2016). Reducing oxidative stress partially rescued DNA damage and partially suppressed GR80 induced cell toxicity in flies (LopezGonzalez et al., 2016). Similarly, restoring the correct redox environment in SOD1 cellular models, also rescued cell death (Ferri et al., 2010), suggesting that ROS production is a driver of neurodegeneration for this model.

\section{Metabolism}

Mitochondria are responsible for the majority of ATP production. When mitochondrial metabolism is disrupted, it affects the respiratory chain and ATP synthesis, which can be yet another mechanism of toxicity for mutations linked to FTD and ALS.

Studies from both patient tissue and disease models suggest that neuronal mitochondrial ATP production is reduced in FTD/ALS. In samples of ALS patients spinal cord, citrate synthase activity and respiration chain function are reduced (Wiedemann et al., 2002). In SOD1-G39A transgenic mice, the ETC is similarly disrupted, with mitochondrial respiration and ATP synthesis reduced at the time of symptom onset but not at earlier stages (Mattiazzi et al., 2002). C9orf72 expansions can also lead to reduced ATP generation: Complex I levels are reduced in C9 patients spinal cord and in C9 patient-derived iPSC cells, leading to a reduction in Complex I activity (Wang et al., 2021). Expression of poly(GR)80 in mice also leads to mitochondrial dysfunction by binding to the ATP5A1 (complex $\mathrm{V}$ ), thus enhancing its ubiquitination and degradation (Choi et al., 2019). Moreover, studies using cultured neurons have shown mutant TDP43 binds and inhibits translation of mRNA of mitochondrially encoded Complex I subunits (Salvatori et al., 2018). Cells derived from patients carrying CHCHD10 mutations are also susceptible to energetic stress and display Complex I deficiency, leading to increased $\mathrm{NADH} / \mathrm{NAD}+$ ratio and diminished tricarboxylic acid (TCA) cycle activity (Straub et al., 2021). Taken together, these studies show that mutations in several, different FTD/ALS-associated genes lead to similar metabolic energy deficiencies, again suggesting that specific mitochondrial impairments might be a common downstream pathogenic mechanisms.

\section{FLY MODELS OF FRONTOTEMPORAL DEMENTIA AND AMYOTROPHIC LATERAL SCLEROSIS AND THEIR ROLE IN MITOCHONDRIAL DYSFUNCTION}

Fly models of FTD/ALS generally use either gain-of -function (overexpression of the chosen gene) or loss-of-function 
(knockdown or knockout of the chosen gene) strategies to investigate disease pathogenesis. The overexpression and/or knockdown or knockout of the desired gene can exhibit a variety of phenotypes such as rough eye, climbing and crawling defects, eclosion defects, or wing defects, all of which suggest toxicity of the introduced genetic modification. These phenotypes can be used as quantifiable readouts of pathogenicity, helping researchers to investigate aspects of FTD/ALS pathogenesis with the goal of elucidating disease mechanisms. Similar to mammalian and human-derived cell models of disease, fly models of FTD/ALS generally display prominent mitochondrial defects, suggesting conserved mechanisms of toxicity and making flies a useful model system to investigate mitochondrial mechanisms of pathogenesis. We will focus here on examples from fly models of the most common disease risk factors: SOD1, TDP43, FUS, and C9orf72 hexanucleotide repeat expansions.

\section{Superoxide Dismutase 1 Fly Models}

Superoxide dismutase 1 is the most extensively investigated gene associated with ALS, especially in rodent models. Of all the FTD/ALS risk genes, SOD1 is one of the most directly related to mitochondrial function as it localizes and aggregates at the intermembrane space (IMS) and the outer mitochondrial membrane (OMM) (Tafuri et al., 2015). SOD1 is a superoxide dismutase which binds zinc and iron and converts superoxide anions into oxygen and hydrogen peroxide (Pardo et al., 1995), thus playing a crucial role in reducing oxidative stress. To date, more than 200 variants have been found in the SOD1 gene $^{4}$. The fly gene ortholog, also named SOD1, shows $67 \%$ amino acid similarity with the human sequence. A number of fly models have been generated looking at SOD1 function in disease development. Both gain and loss of function models have been generated, as it is still a matter of debate whether ALS caused by SOD1 mutations is due to a gain or loss of function of the protein (Mockett et al., 2003; Şahin et al., 2017; Agudelo et al., 2020).

Fly models expressing mutant SOD1 display motor defects (Bahadorani et al., 2013; Gallart-Palau et al., 2016), both when expressed in muscle (Gallart-Palau et al., 2016) and the brain (Bahadorani et al., 2013). In each case, locomotor dysfunction is accompanied by mitochondrial defects. Flies over-expressing zinc deficient human SOD1 also show cristae vacuolization and reduced ATP levels in fly heads but not in bodies (Bahadorani et al., 2013), and are severely sensitized to paraquat and zinc. Both paraquat and zinc act as mitochondria toxins, with paraquat inhibiting mitochondrial complex I activity and zinc interacting with nitric oxide to cause mitochondrial dysfunction. Flies expressing SOD1G93A, an extensively modeled dominant causal mutation, also show defects in mitochondrial morphology (Gallart-Palau et al., 2016), similar to mitochondrial defects observed in mouse models of SOD1-G93A (Higgins et al., 2003). Taken together, these studies suggest the effects of SOD1 mutations

${ }^{4}$ https://alsod.ac.uk/output/gene.php/SOD1\#variants on mitochondrial dysfunction are well conserved between flies and mammals.

\section{TDP-43 Fly Models}

TDP-43 is an RNA/DNA binding protein involved in RNA metabolism. Neuronal inclusion bodies of hyperphosphorylated and ubiquitinated TDP-43 deposits were first described in the brain and spinal cord of FTD/ALS patients (Arai et al., 2006; Neumann et al., 2006). In healthy conditions, TDP43 localizes to the nucleus; however, in pathological conditions, TDP-43 translocates to the cytoplasm where it forms inclusions or aggregates (Ayala et al., 2008). The presence of cytoplasmic inclusions of TDP-43 suggests a toxic gain-of-function disease mechanism; in contrast, the loss of TDP-43 from the nucleus could also indicate a loss-of-function mechanism (Neumann et al., 2006; Winton et al., 2008; Giordana et al., 2010). TBPH is the fly TDP-43 ortholog, with 53\% amino acid similarity between fly and human sequences. Reduction of TBPH, either by RNAi or genetic null mutants, reduces lifespan in flies and leads to a decline in motor function (Feiguin et al., 2009; Lu et al., 2009; Lin et al., 2011; Diaper et al., 2013), conversely, expression of human TDP-43 can rescue the loss of function phenotypes (Wang et al., 2011). Loss of TBPH function also causes reduced mitochondrial axonal transport linked to severe motor impairment (Baldwin et al., 2016), adding weight to TDP43 loss of function as a disease mechanism. However, another study over-expressing wildtype human TDP-43 or A315T-mutant TDP-43 in the fly eye showed activation of mitochondrial unfolded protein response (UPRmt) and increased mitochondrial ROS levels in motor neurons (Wang et al., 2019), suggesting that both gain and loss-of-function of TDP43 can contribute to mitochondrial defects.

A number of studies have shown that over-expression of human wildtype TDP-43 in flies, either in muscle (Altanbyek et al., 2016) or neurons (Khalil et al., 2017), leads to aberrant mitochondrial morphology. Mitochondria appear fragmented, and the expression of well-known regulators of mitochondrial dynamics, such as mitochondrial assembly regulatory factor (Marf), which promotes fusion, are decreased both in muscle (Altanbyek et al., 2016) and brain (Khalil et al., 2017). Overexpression of Marf in muscle partially rescues mitochondrial morphology (Altanbyek et al., 2016), and its over-expression in neurons partially rescues the locomotor phenotypes and neuromuscular junction (NMJ) defects associated with TDP43 over-expression (Khalil et al., 2017). Downregulation of a dynamin-like GTPase that mediates mitochondrial fission, Drp1, similarly leads to partial rescue of TDP-43 phenotypes in brain and muscle (Altanbyek et al., 2016; Khalil et al., 2017), confirming that dysfunction in mitochondrial dynamics contributes at least partially to TDP-43 toxicity. Similar defects to those in TDP-43 over-expression have been observed in flies over-expressing human FUS and TATA box-binding proteinassociated factor 15 (TAF15), two additional ALS-associated genes, suggesting conserved mechanisms of pathogenicity (Altanbyek et al., 2016). The ease of generating transgenic flies and conducting rapid phenotypic analysis in flies allows for these comparisons across a number of models of disease, which would 
otherwise be more costly and time consuming in mammalian models of disease.

\section{Fused in Sarcoma Fly Models}

Fused in sarcoma, similarly to TDP-43, is involved in RNArelated metabolism (Lagier-Tourenne et al., 2010) and is usually located in nucleus. Like TDP-43, abnormal cytoplasmic inclusions of FUS are formed in ALS. However, FUS and TDP-43 may act independently in ALS pathogenesis given the absence of TDP-43 pathology in FUS mutant patients (Kwiatkowski et al., 2009; Vance et al., 2009). Additionally, ALS patients with FUS mutations display a more aggressive disease form, with earlier symptom onset and shorter symptoms duration, as well as increased rate of bulbar onset (Yan et al., 2010). FUS is conserved in flies, where the orthologous gene cabeza (caz) shows $51 \%$ amino acid similarity to the human gene product (Stolow and Haynes, 1995). Importantly, expression of human FUS can rescue caz mutant phenotype (Wang et al., 2011), demonstrating functional equivalence of the orthologous genes.

As in TDP-43-mediated toxicity, FUS-mediated toxicity may result from either gain-of-function or loss-of-function mechanisms. In flies, overexpression of wildtype caz, overexpression of mutant caz P398L (carrying an equivalent mutation to the human pathogenic P525L mutation), or loss of caz can all result in inhibited mitochondrial transport, with mutant caz over-expression showing the most severe mitochondrial transport impairment and greatest effects on development and locomotor activity (Baldwin et al., 2016).

FUS fly models also display prominent mitochondrial defects: wildtype or P525L FUS over-expression in adult flies leads to mitochondrial fragmentation, as seen for TDP43 (Deng et al., 2015). Both wildtype and P525L mutant FUS interact with the catalytic subunit of mitochondrial ATP synthase (ATP5B) in cells and disrupt ATP synthase supercomplex (complex V) function and formation in flies, leading to the activation of the UPRmt (Deng et al., 2018). Down-regulation of ATP5B or genes involved in UPRmt partially rescues neurodegenerative phenotypes (Deng et al., 2018), suggesting that the impaired ETC and subsequent activation of the UPRmt can at least partially drive neurodegeneration. Downregulation of Hsp60, an ATPdependent mitochondrial chaperone protein that modulates the localization of FUS to mitochondria in human cells, also partially rescues the rough eye phenotype and locomotor dysfunction observed in FUS transgenic flies (Deng et al., 2015).

These studies in flies suggest that the mitochondrial phenotypes associated with FUS and TDP43 fly models are very similar, pointing toward common downstream pathogenic mechanisms. Importantly, these findings suggest that therapies targeted to these mechanisms might be promising areas for study in multiple types of FTD/ALS.

\section{C9orf72 Hexonucleotide Repeat Expansion Fly Model}

A hexanucleotide repeat expansion in the gene C9orf72 is the most common genetic cause of ALS and FTD (Chiò et al., 2012).
Since this expansion is a relatively recently identified cause of FTD/ALS, much of our understanding of the pathogenic mechanisms of this expansion derives from models that can be rapidly generated and characterized - namely Drosophila models (Xu et al., 2013; Mizielinska et al., 2014; Freibaum et al., 2015).

Three mechanism of C9 toxicity have been proposed: (1) loss-of-function caused by reduction of endogenous C9orf72 transcription, (2) gain-of-function by formation of nuclear RNA foci transcribed from the $\mathrm{G}_{4} \mathrm{C}_{2}$ repeats, and (3) gain-of-function by the accumulation of highly repetitive dipeptide repeats proteins (DPRs) translated from the expanded repeats (Ash et al., 2013; Mori et al., 2013; Mizielinska et al., 2014). These DPRs can be translated from either sense $\left(\mathrm{G}_{4} \mathrm{C}_{2}\right)$ or antisense $\left(\mathrm{G}_{2} \mathrm{C}_{4}\right)$ transcripts through repeat-associated non-AUG (RAN) translation (Mori et al., 2013; Gendron et al., 2014). C9orf72 does not have a fly ortholog, so fly models have relied instead on overexpression of abnormal $\mathrm{G}_{4} \mathrm{C}_{2}$ repeats and DPR proteins to investigate potential gain-of-function mechanisms. The lack of an orthologous genes is both a strength and limitation of Drosophila in this case: the endogenous function of C9orf72 cannot be easily investigated using fly models, but the effects of the expansion can be isolated from the downregulation of the endogenous gene.

Over-expression of a variety of repeat lengths, from 30 $\mathrm{G}_{4} \mathrm{C}_{2}$ repeats to over 100 , has been shown to lead to retinal degeneration in the eye, shortening of lifespan and impaired motor function (Xu et al., 2013; Mizielinska et al., 2014; Wen et al., 2014; Freibaum et al., 2015; Tran et al., 2015), suggesting that the repeats are highly toxic to neurons. As additional evidence of dose-dependent effects of toxicity, increasing repeat lengths show increased toxicity (Mizielinska et al., 2014). Mizielinska et al. (2014) showed that toxicity was most directly associated with the arginine-rich DPRs, GR and PR, a finding that has been confirmed in independent fly models (Wen et al., 2014; Tao et al., 2015; Yang et al., 2015; Boeynaems et al., 2016) as well as in mammalian systems (Shi et al., 2017; Zhang Y. J. et al., 2018; Choi et al., 2019; Zhang et al., 2019; Cook et al., 2020).

As seen in other genetic causes of FTD/ALS, $\mathrm{G}_{4} \mathrm{C}_{2}$ expansions can produce a number of mitochondrial deficits. Expression of $\mathrm{G}_{4} \mathrm{C}_{2}(36)$ repeats disrupts mitochondrial transport when expressed in fly motor neurons (Baldwin et al., 2016). In fly muscle cells, poly(GR), which is highly positively charged, has been shown to enter mitochondria, disrupt cristae junction structure, increase membrane potential, and increase the formation of ROS (Li et al., 2020). GR80 binds to components of the Mitochondrial Contact Site and Cristae Organizing System (MICOS) complex, which is involved in cristae junction formation; the MICOS complex thus represents a potential mechanism by which GR80 can impair the exchange of mitochondrial metabolites and osmolytes. Consistent with this mechanism, downregulation of MICOS complex components in a fly model of GR toxicity rebalances ion homeostasis, reduces GR80 levels, and improves GR80 toxicity (Li et al., 2020). Rebalancing mitochondrial matrix ion levels with the $\mathrm{K}+/ \mathrm{H}+$ antiporter nigericin also rescues mitochondrial 


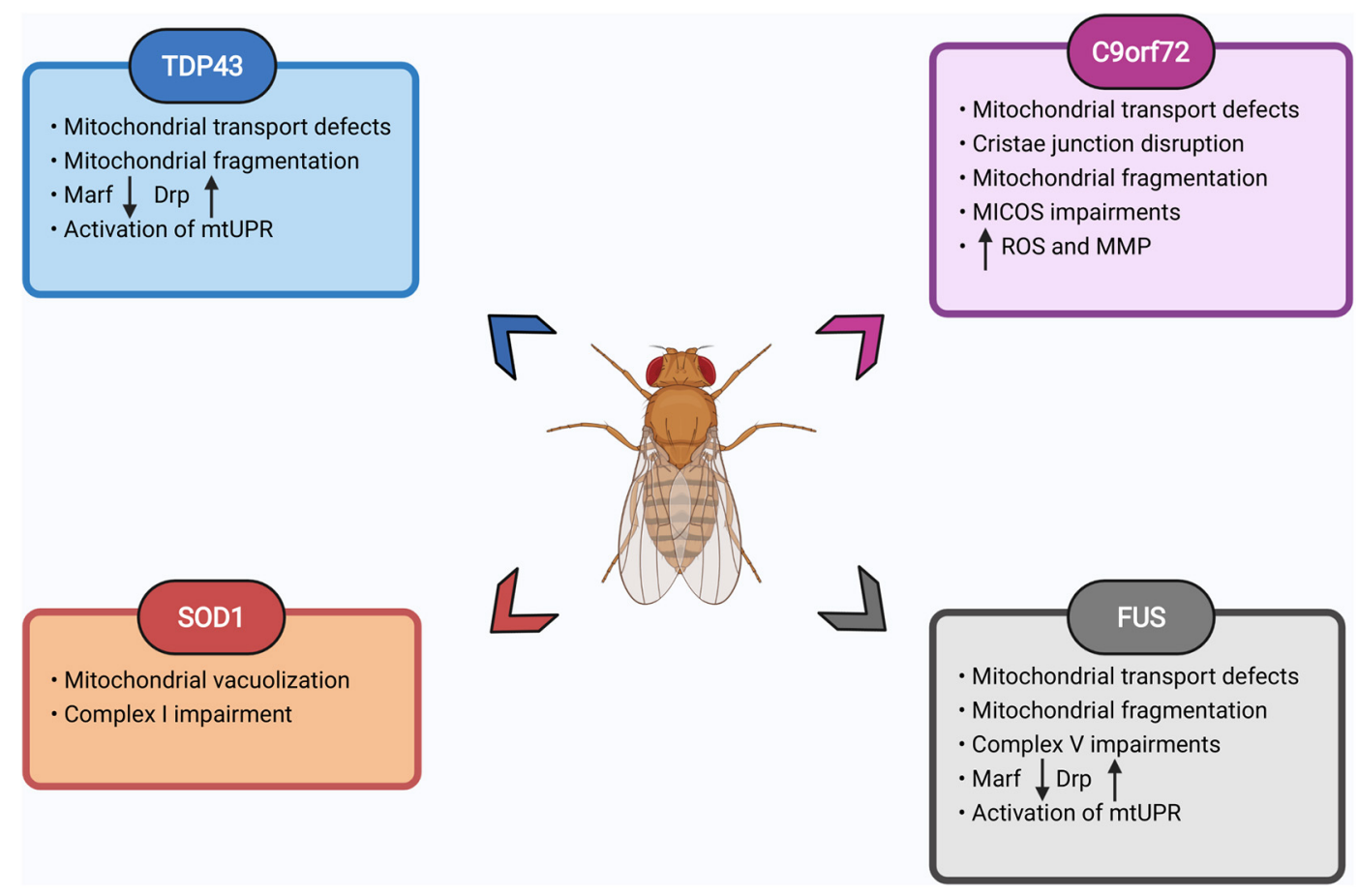

FIGURE 5 | Summary of mitochondrial defects observed in fly FTD/ALS models. List of prominent mitochondrial impairments observed in fly models of TDP43, SOD1, FUS, and C9orf72 expansion. Please see text for details. Images created with BioRender.com.

cristae morphology in GR(80) expressing flies ( $\mathrm{Li}$ et al., 2020). Maintenance of appropriate MICOS complex activity is essential to mitochondrial homeostasis both in health and in disease: a recent study has found that knockdown of Drosophila MICOS genes phenocopies many of the features observed in C9orf72 models, including cristae junction loss in muscles, low mitochondrial membrane potential, imbalanced fusion/fission machinery, increased mitophagy, limited cell death, and reduced climbing ability (Wang et al., 2020). CHCHD10 mutations have also been implicated in MICOS complex integrity (Genin et al., 2018), again suggesting common mitochondrial related impairments driving toxicity in FTD/ALS. The role of MICOS might also not be limited to FTD/ALS: Pink1, a gene implicated in autosomal recessive Parkinson's disease, has also been shown to regulate MICOS components (Tsai et al., 2018), suggesting common elements across multiple neurodegenerative disorders.

\section{DISCUSSION/CONCLUSION}

In summary, Drosophila models of FTD/ALS display conserved pathological changes, demonstrating they can be rapid engines for the discovery of pathogenic mechanisms in neurodegenerative diseases. Flies have helped address questions about mitochondrial function and dysfunction in neurodegenerative diseases, aging, mitochondrial diseases, and developmental biology. Their extensive genetic tools, potential for large unbiased screens, and cost effectiveness has allowed Drosophila to provide key insights in understanding mitochondrial biology in FTD/ALS models (Figure 5). Drosophila is uniquely placed, given its facile genetics, to study convergent mechanisms of disease across multiple mutations, allowing genetic rescue experiments at scale to rapidly identify causative pathways in disease development. Drosophila also allows for screens to identify genetic or pharmacological interventions that ameliorate organismal health in addition to cellular toxicity, a potential advantage over cellular screening platforms.

In particular, flies could be used to address some of the following outstanding questions:

- In addition to GR, how does concurrent expression of all possible DPRs, and combinations of DPRs, from C9 repeats affect mitochondrial biology?

- Does the rescue of specific mitochondrial defects, for example MICOS integrity or Complex I activity, rescue lifespan and healthspan across models of multiple diseaseassociated mutations?

- Flies possess unique genetic toolsets that allow precise celltype-specific and temporal control of gene expression. This places them in an ideal setting to address questions of cell-type and age-related susceptibility to disease. Why are certain neuronal populations most susceptible to the mutations that cause disease, and why only later in life? Are mitochondrial defects the first observable impairment, or do they follow other markers of neurodegeneration? 
- Conversely, the same temporally controlled genetic tools can be used to answer questions related to therapeutic development. Can the rescue of a mitochondrial defect later on in disease development still rescue animal health, suggesting it could be a useful therapeutic avenue for patients already displaying symptoms?

Future research using Drosophila, particularly when complemented with confirmatory studies in mammalian or human systems, therefore has the potential to speed up and offer more thorough understanding of therapeutic strategies to address devastating neurodegenerative diseases.

\section{REFERENCES}

Abou-Sleiman, P. M., Muqit, M. M., and Wood, N. W. (2006). Expanding insights of mitochondrial dysfunction in Parkinson's disease. Nat. Rev. Neurosci. 7, 207-219. doi: 10.1038/nrn1868

Agudelo, A., St Amand, V., Grissom, L., Lafond, D., Achilli, T., Sahin, A., et al. (2020). Age-dependent degeneration of an identified adult leg motor neuron in a Drosophila SOD1 model of ALS. Biol. Open 9:bio049692. doi: 10.1242/bio. 049692

Alami, N. H., Smith, R. B., Carrasco, M. A., Williams, L. A., Winborn, C. S., Han, S. S. W., et al. (2014). Axonal Transport of TDP-43 mRNA granules is impaired by ALS-Causing mutations. Neuron 81, 536-543. doi: 10.1016/j.neuron.2013. 12.018

Albrecht, S. C., Barata, A. G., Großhans, J., Teleman, A. A., and Dick, T. P. (2011). In Vivo mapping of hydrogen peroxide and oxidized glutathione reveals chemical and regional specificity of redox homeostasis. Cell Metab. 14, 819-829. doi: 10.1016/j.cmet.2011.10.010

Alsultan, A. A., Waller, R., Heath, P. R., and Kirby, J. (2016). The genetics of amyotrophic lateral sclerosis: current insights. Degener. Neurol. Neuromuscul. Dis. 6, 49-64. doi: 10.2147/DNND.S84956

Altanbyek, V., Cha, S. J., Kang, G. U., Im, D. S., Lee, S., Kim, H. J., et al. (2016). Imbalance of mitochondrial dynamics in Drosophila models of amyotrophic lateral sclerosis. Biochem. Biophys. Res. Commun. 481, 259-264. doi: 10.1016/j. bbrc.2016.10.134

Anandatheerthavarada, H. K., and Devi, L. (2007). Amyloid precursor protein and mitochondrial dysfunction in Alzheimer's disease. Neuroscientist 13, 626-638. doi: $10.1177 / 1073858407303536$

Arai, T., Hasegawa, M., Akiyama, H., Ikeda, K., Nonaka, T., Mori, H., et al. (2006). TDP-43 is a component of ubiquitin-positive tau-negative inclusions in frontotemporal lobar degeneration and amyotrophic lateral sclerosis. Biochem. Biophys. Res. Commun. 351, 602-611. doi: 10.1016/j.bbrc.2006.10.093

Arce-Molina, R., Cortés-Molina, F., Sandoval, P. Y., Galaz, A., Alegría, K., Schirmeier, S., et al. (2020). A highly responsive pyruvate sensor reveals pathway-regulatory role of the mitochondrial pyruvate carrier MPC. Elife 9:e53917. doi: 10.7554/eLife.53917

Ash, P. E., Bieniek, K. F., Gendron, T. F., Caulfield, T., Lin, W.-L., DejesusHernandez, M., et al. (2013). Unconventional translation of C9ORF72 GGGGCC expansion generates insoluble polypeptides specific to c9FTD/ALS. Neuron 77, 639-646. doi: 10.1016/j.neuron.2013.02.004

Ashburner, M., and Bergman, C. M. (2005). Drosophila melanogaster: a case study of a model genomic sequence and its consequences. Genome Res. 15, 1661-1667. doi: $10.1101 /$ gr.3726705

Ayala, Y. M., Zago, P., D’Ambrogio, A., Xu, Y.-F., Petrucelli, L., Buratti, E., et al. (2008). Structural determinants of the cellular localization and shuttling of TDP-43. J. Cell Sci. 121, 3778-3785. doi: 10.1242/jcs.038950

Bahadorani, S., Mukai, S. T., Rabie, J., Beckman, J. S., Phillips, J. P., and Hilliker, A. J. (2013). Expression of zinc-deficient human superoxide dismutase in Drosophila neurons produces a locomotor defect linked to mitochondrial dysfunction. Neurobiol. Aging 34, 2322-2330. doi: 10.1016/j.neurobiolaging. 2013.03.024

\section{AUTHOR CONTRIBUTIONS}

SA and TN wrote the manuscript. NW edited the manuscript. All authors contributed to the article and approved the submitted version.

\section{FUNDING}

This study was supported by the Alzheimer's Society fellowship AS-JF-17b-011 (NW), ARUK Senior Fellowship ARUKSRF2018A-003 (TN), MRC grant MR/V003585/1 (TN), and The Council of Trust for the People (MARA) (SA).

Baker, K. D., and Thummel, C. S. (2007). Diabetic larvae and obese flies-emerging studies of metabolism in Drosophila. Cell Metab. 6, 257-266. doi: 10.1016/j. cmet.2007.09.002

Baker, M., Mackenzie, I. R., Pickering-Brown, S. M., Gass, J., Rademakers, R., Lindholm, C., et al. (2006). Mutations in progranulin cause tau-negative frontotemporal dementia linked to chromosome 17. Nature 442, 916-919. doi: 10.1038 /nature05016

Baker, N. E. (1987). Molecular cloning of sequences from wingless, a segment polarity gene in Drosophila: the spatial distribution of a transcript in embryos. EMBO J. 6, 1765-1773. doi: 10.1002/j.1460-2075.1987.tb 02429.x

Baldwin, K. R., Godena, V. K., Hewitt, V. L., and Whitworth, A. J. (2016). Axonal transport defects are a common phenotype in Drosophila models of ALS. Hum. Mol. Genet. 25, 2378-2392. doi: 10.1093/hmg/ddw105

Bangi, E., Ang, C., Smibert, P., Uzilov, A. V., Teague, A. G., Antipin, Y., et al. (2019). A personalized platform identifies trametinib plus zoledronate for a patient with KRAS-mutant metastatic colorectal cancer. Sci. Adv. 5:eaav6528. doi: $10.1126 /$ sciadv.aav6528

Bannwarth, S., Ait-El-Mkadem, S., Chaussenot, A., Genin, E. C., Lacas-Gervais, S., Fragaki, K., et al. (2014). A mitochondrial origin for frontotemporal dementia and amyotrophic lateral sclerosis through CHCHD10 involvement. Brain 137, 2329-2345. doi: 10.1093/brain/awu138

Barrientos, A. (2002). In vivo and in organello assessment of OXPHOS activities. Methods 26, 307-316. doi: 10.1016/S1046-2023(02)00036-1

Barrientos, A., Fontanesi, F., and Díaz, F. (2009). Evaluation of the mitochondrial respiratory chain and oxidative phosphorylation system using polarography and spectrophotometric enzyme assays. Curr. Protoc. Hum. Genet. 63, 19-23. doi: 10.1002/0471142905.hg1903s63

Bate, M., and Arias, A. M. (1993). The Development of Drosophila Melanogaster. New York: Cold Spring Harbor Laboratory Press.

Bäumer, D., East, S. Z., Tseu, B., Zeman, A., Hilton, D., Talbot, K., et al. (2014). FTLD-ALS of TDP-43 type and SCA2 in a family with a full ataxin2 polyglutamine expansion. Acta Neuropathol. 128, 597-604. doi: 10.1007/ s00401-014-1277-z

Beal, M. F., Ferrante, R. J., Browne, S. E., Matthews, R. T., Kowall, N. W., and Brown, R. H. Jr. (1997). Increased 3-nitrotyrosine in both sporadic and familial amyotrophic lateral sclerosis. Ann. Neurol. 42, 644-654. doi: 10.1002/ana. 410420416

Beckwith, E. J., and French, A. S. (2019). Sleep in drosophila and its context. Front. Physiol. 10:1167. doi: 10.3389/fphys.2019.01167

Bejsovec, A. (2018). Wingless signaling: a genetic journey from morphogenesis to metastasis. Genetics 208, 1311-1336. doi: 10.1534/genetics.117.300157

Belfiori-Carrasco, L. F., Marcora, M. S., Bocai, N. I., Ceriani, M. F., Morelli, L., and Castaño, E. M. (2017). A novel genetic screen identifies modifiers of agedependent amyloid $\beta$ toxicity in the drosophila brain. Front. Aging Neurosci. 9:61. doi: 10.3389/fnagi.2017.00061

Bellen, H. J., Levis, R. W., Liao, G., He, Y., Carlson, J. W., Tsang, G., et al. (2004). The BDGP gene disruption project: single transposon insertions associated with $40 \%$ of Drosophila genes. Genetics 167, 761-781. doi: 10.1534/genetics.104. 026427 
Bensimon, G., Lacomblez, L., and Meininger, V. (1994). A controlled trial of riluzole in amyotrophic lateral sclerosis. ALS/RiluzoleStudy Group. N. Engl. J. Med. 330, 585-591. doi: 10.1056/NEJM199403033300901

Benzer, S. (1967). Behavioral mutants of drosophila isolated by countercurrent distribution. Proc. Natl. Acad. Sci. U. S. A. 58, 1112-1119. doi: 10.1073/pnas. 58.3.1112

Bertolin, G., Bulteau, A. L., Alves-Guerra, M. C., Burel, A., Lavault, M. T., Gavard, O., et al. (2018). Aurora kinase a localises to mitochondria to control organelle dynamics and energy production. Elife 7:e38111. doi: 10.7554/eLife.38111

Bharucha, K. N. (2009). The epicurean fly: using drosophila melanogaster to study metabolism. Pediatr. Res. 65, 132-137. doi: 10.1203/PDR.0b013e318191fc68

Bhatti, J. S., Bhatti, G. K., and Reddy, P. H. (2017). Mitochondrial dysfunction and oxidative stress in metabolic disorders - A step towards mitochondria based therapeutic strategies. Biochim. Biophys. Acta Mol. Basis Dis. 1863, 1066-1077. doi: $10.1016 /$ j.bbadis.2016.11.010

Bilen, J., and Bonini, N. M. (2007). Genome-wide screen for modifiers of ataxin3 neurodegeneration in drosophila. PLoS Genet. 3:e177. doi: 10.1371/journal. pgen.0030177

Bilsland, L. G., Sahai, E., Kelly, G., Golding, M., Greensmith, L., and Schiavo, G. (2010). Deficits in axonal transport precede ALS symptoms in vivo. Proc. Natl. Acad. Sci. U. S. A. 107, 20523-20528. doi: 10.1073/pnas. 1006869107

Birch-Machin, M. A., and Turnbull, D. M. (2001). "Chapter 5 Assaying mitochondrial respiratory complex activity in mitochondria isolated from human cells and tissues," in Mitochondria, eds L. A. Pon and E. A. Schon (Cambridge: Academic Press), 97-117. doi: 10.1016/s0091-679x(01)65006-4

Bischof, J., Björklund, M., Furger, E., Schertel, C., Taipale, J., and Basler, K. (2013). A versatile platform for creating a comprehensive UAS-ORFeome library in Drosophila. Development 140, 2434-2442. doi: 10.1242/dev.088757

Boeynaems, S., Bogaert, E., Michiels, E., Gijselinck, I., Sieben, A., Jovièiæ, A., et al. (2016). Drosophila screen connects nuclear transport genes to DPR pathology in c9ALS/FTD. Sci. Rep. 6:20877. doi: 10.1038/srep20877

Bonnay, F., Veloso, A., Steinmann, V., Köcher, T., Abdusselamoglu, M. D., Bajaj, S., et al. (2020). Oxidative metabolism drives immortalization of neural stem cells during tumorigenesis. Cell 182, 1490-1507.e19. doi: 10.1016/j.cell.2020.07.039

Bosetti, F., Brizzi, F., Barogi, S., Mancuso, M., Siciliano, G., Tendi, E. A., et al. (2002). Cytochrome $\mathrm{c}$ oxidase and mitochondrial F1F0-ATPase (ATP synthase) activities in platelets and brain from patients with Alzheimer's disease. Neurobiol. Aging 23, 371-376. doi: 10.1016/s0197-4580(01)00314-1

Brand, A. H., and Perrimon, N. (1993). Targeted gene expression as a means of altering cell fates and generating dominant phenotypes. Development 118, 401-415. doi: 10.1242/dev.118.2.401

Brown, D. G., Shorter, J., and Wobst, H. J. (2020). Emerging smallmolecule therapeutic approaches for amyotrophic lateral sclerosis and frontotemporal dementia. Bioorganic Med. Chem. Lett. 30:126942. doi:10.1016/j.bmcl.2019.126942.

Buchanan, R. L., and Benzer, S. (1993). Defective Glia in the Drosophila Brain Degeneration Mutant drop-dead. Neuron 10, 839-850. doi: 10.1016/08966273(93)90200-B

Burman, J. L., Itsara, L. S., Kayser, E. B., Suthammarak, W., Wang, A. M., Kaeberlein, M., et al. (2014). A Drosophila model of mitochondrial disease caused by a complex I mutation that uncouples proton pumping from electron transfer. Dis. Model. Mech. 7, 1165-1174. doi: 10.1242/dmm.015321

Butzlaff, M., Hannan, S. B., Karsten, P., Lenz, S., Ng, J., Voßfeldt, H., et al. (2015). Impaired retrograde transport by the Dynein/Dynactin complex contributes to Tau-induced toxicity. Hum. Mol. Genet. 24, 3623-3637. doi: 10.1093/hmg/ ddv 107

Byrne, S., Walsh, C., Lynch, C., Bede, P., Elamin, M., Kenna, K., et al. (2011). Rate of familial amyotrophic lateral sclerosis: a systematic review and metaanalysis. J. Neurol. Neurosurg. Psychiatry 82, 623-627. doi: 10.1136/jnnp.2010. 224501

Casterton, R. L., Hunt, R. J., and Fanto, M. (2020). Pathomechanism heterogeneity in the amyotrophic lateral sclerosis and frontotemporal dementia disease spectrum: providing focus through the lens of autophagy. J. Mol. Biol. 432, 2692-2713. doi: 10.1016/j.jmb.2020.02.018

Celotto, A. M., Frank, A. C., McGrath, S. W., Fergestad, T., Van Voorhies, W. A., Buttle, K. F., et al. (2006). Mitochondrial encephalomyopathy in drosophila. J. Neurosci. 26, 810-820. doi: 10.1523/JNEUROSCI.4162-05. 2006
Chen, L., Na, R., Danae McLane, K., Thompson, C. S., Gao, J., Wang, X., et al. (2021). Overexpression of ferroptosis defense enzyme Gpx4 retards motor neuron disease of SOD1G93A mice. Sci. Rep. 11:12890. doi: 10.1038/s41598021-92369-8

Chen, Z., Zhang, F., and Xu, H. (2019). Human mitochondrial DNA diseases and Drosophila models. J. Genet. Genomics 46, 201-212. doi: 10.1016/j.jgg.2019.03. 009

Chiò, A., Calvo, A., Mazzini, L., Cantello, R., Mora, G., Moglia, C., et al. (2012). Extensive genetics of ALS: a population-based study in Italy. Neurology 79, 1983-1989. doi: 10.1212/WNL.0b013e3182735d36

Choi, S. Y., Lopez-Gonzalez, R., Krishnan, G., Phillips, H. L., Li, A. N., Seeley, W. W., et al. (2019). C9ORF72-ALS/FTD-associated poly(GR) binds Atp5al and compromises mitochondrial function in vivo. Nat. Neurosci. 22, 851-862. doi: 10.1038/s41593-019-0397-0

Chowdhary, S., Tomer, D., Dubal, D., Sambre, D., and Rikhy, R. (2017). Analysis of mitochondrial organization and function in the Drosophila blastoderm embryo. Sci. Rep. 7:5502. doi: 10.1038/s41598-017-05679-1

Cirulli, E. T., Lasseigne, B. N., Petrovski, S., Sapp, P. C., Dion, P. A., Leblond, C. S., et al. (2015). Exome sequencing in amyotrophic lateral sclerosis identifies risk genes and pathways. Science 347, 1436-1441. doi: 10.1126/science.aaa3650

Clancy, D. J., Gems, D., Harshman, L. G., Oldham, S., Stocker, H., Hafen, E., et al. (2001). Extension of life-span by loss of CHICO, a Drosophila insulin receptor substrate protein. Science 292, 104-106. doi: 10.1126/science.1057991

Clark, I. E., Dodson, M. W., Jiang, C., Cao, J. H., Huh, J. R., Seol, J. H., et al. (2006). Drosophila pink1 is required for mitochondrial function and interacts genetically with parkin. Nature 441, 1162-1166. doi: 10.1038/nature04779

Cochemé, H. M., Quin, C., McQuaker, S. J., Cabreiro, F., Logan, A., Prime, T. A., et al. (2011). Measurement of $\mathrm{H} 2 \mathrm{O} 2$ within living drosophila during aging using a ratiometric mass spectrometry probe targeted to the mitochondrial matrix. Cell Metab. 13, 340-350. doi: 10.1016/j.cmet.2011.02.003

Cook, C. N., Wu, Y., Odeh, H. M., Gendron, T. F., Jansen-West, K., del Rosso, G., et al. (2020). C9orf72 poly(GR) aggregation induces TDP-43 proteinopathy. Sci. Transl. Med. 12:eabb3774. doi: 10.1126/scitranslmed.abb3774

Cooper-Knock, J., Walsh, M. J., Higginbottom, A., Robin Highley, J., Dickman, M. J., Edbauer, D., et al. (2014). Sequestration of multiple RNA recognition motif-containing proteins by C9orf72 repeat expansions. Brain 137, 2040-2051. doi: 10.1093/brain/awu120

Costa, A. C., Loh, S. H. Y., and Martins, L. M. (2013). Drosophila Trap1 protects against mitochondrial dysfunction in a PINK1/parkin model of Parkinson's disease. Cell Death Dis. 4:e467. doi: 10.1038/cddis.2012.205

Cozzolino, M., and Carrì, M. T. (2012). Mitochondrial dysfunction in ALS. Prog. Neurobiol. 97, 54-66. doi: 10.1016/j.pneurobio.2011.06.003

Cruts, M., Gijselinck, I., van der Zee, J., Engelborghs, S., Wils, H., Pirici, D., et al. (2006). Null mutations in progranulin cause ubiquitin-positive frontotemporal dementia linked to chromosome 17q21. Nature 442, 920-924. doi: 10.1038/ nature 05017

Dafinca, R., Scaber, J., Ababneh, N., Lalic, T., Weir, G., Christian, H., et al. (2016). C9orf72 hexanucleotide expansions are associated with altered endoplasmic reticulum calcium homeostasis and stress granule formation in induced pluripotent stem cell-derived neurons from patients with amyotrophic lateral sclerosis and frontotemporal demen. Stem Cells 34, 2063-2078. doi: 10.1002/ stem. 2388

Damiano, M., Starkov, A. A., Petri, S., Kipiani, K., Kiaei, M., Mattiazzi, M., et al. (2006). Neural mitochondrial Ca2+ capacity impairment precedes the onset of motor symptoms in G93A Cu/Zn-superoxide dismutase mutant mice. J. Neurochem. 96, 1349-1361. doi: 10.1111/j.1471-4159.2006.03619.x

De Robertis, E. M., and Sasai, Y. (1996). A common plan for dorsoventral patterning in Bilateria. Nature 380, 37-40. doi: 10.1038/380037a0

DeJesus-Hernandez, M., Mackenzie, I. R., Boeve, B. F., Boxer, A. L., Baker, M., Rutherford, N. J., et al. (2011). Expanded GGGGCC hexanucleotide repeat in noncoding region of C9ORF72 causes chromosome 9p-Linked FTD and ALS. Neuron 72, 245-256. doi: 10.1016/j.neuron.2011.09.011

Deng, H., Dodson, M. W., Huang, H., and Guo, M. (2008). The Parkinson's disease genes pink1 and parkin promote mitochondrial fission and/or inhibit fusion in Drosophila. Proc. Natl. Acad. Sci. U. S. A. 105, 14503-14508. doi: 10.1073/pnas. 0803998105

Deng, H.-X., Chen, W., Hong, S.-T., Boycott, K. M., Gorrie, G. H., Siddique, N., et al. (2011). Mutations in UBQLN2 cause dominant X-linked juvenile 
and adult-onset ALS and ALS/dementia. Nature 477, 211-215. doi: 10.1038/ nature10353

Deng, J., Wang, P., Chen, X., Cheng, H., Liu, J., Fushimi, K., et al. (2018). FUS interacts with ATP synthase beta subunit and induces mitochondrial unfolded protein response in cellular and animal models. Proc. Natl. Acad. Sci. U. S. A. 115, E9678-E9686. doi: 10.1073/pnas.1806655115

Deng, J., Yang, M., Chen, Y., Chen, X., Liu, J., Sun, S., et al. (2015). FUS interacts with HSP60 to promote mitochondrial damage. PLoS Genet. 11:e1005357. doi: 10.1371/journal.pgen.1005357

DeVorkin, L., Go, N. E., Hou, Y.-C. C., Moradian, A., Morin, G. B., and Gorski, S. M. (2014). The Drosophila effector caspase Dcp-1 regulates mitochondrial dynamics and autophagic flux via SesB. J. Cell Biol. 205, 477-492. doi: 10.1083/ jcb.201303144

Diaper, D. C., Adachi, Y., Lazarou, L., Greenstein, M., Simoes, F. A., Di Domenico, A., et al. (2013). Drosophila TDP-43 dysfunction in glia and muscle cells cause cytological and behavioural phenotypes that characterize ALS and FTLD. Hum. Mol. Genet. 22, 3883-3893. doi: $10.1093 / \mathrm{hmg} / \mathrm{ddt} 243$

Dietzl, G., Chen, D., Schnorrer, F., Su, K.-C., Barinova, Y., Fellner, M., et al. (2007). A genome-wide transgenic RNAi library for conditional gene inactivation in Drosophila. Nature 448, 151-156. doi: 10.1038/nature05954

Doherty, J., Logan, M. A., Taşdemir, O. E., and Freeman, M. R. (2009). Ensheathing glia function as phagocytes in the adult Drosophila brain. J. Neurosci. 29, 4768-4781. doi: 10.1523/JNEUROSCI.5951-08.2009

Duffy, J. B. (2002). GAL4 system in Drosophila: a fly geneticist's Swiss army knife. Genesis 34, 1-15. doi: 10.1002/gene.10150

Elden, A. C., Kim, H.-J., Hart, M. P., Chen-Plotkin, A. S., Johnson, B. S., Fang, X., et al. (2010). Ataxin-2 intermediate-length polyglutamine expansions are associated with increased risk for ALS. Nature 466, 1069-1075. doi: 10.1038/ nature 09320

Elisa, R., Rainero, I., Chiò, A., Rogaeva, E., Galimberti, D., Fenoglio, P., et al. (2012). SQSTM1 mutations in frontotemporal lobar degeneration and amyotrophic lateral sclerosis. Neurology 79, 1556-1562. doi: 10.1212/WNL. ob013e31826e25df

Fallini, C., Khalil, B., Smith, C. L., and Rossoll, W. (2020). Traffic jam at the nuclear pore: all roads lead to nucleocytoplasmic transport defects in ALS/FTD. Neurobiol. Dis. 140:104835. doi: 10.1016/j.nbd.2020.104835

Feany, M. B., and Bender, W. W. (2000). A Drosophila model of Parkinson's disease. Nature 404, 394-398. doi: 10.1038/35006074

Fecto, F., and Siddique, T. (2011). Making connections: pathology and genetics link amyotrophic lateral sclerosis with frontotemporal lobe dementia. J. Mol. Neurosci. 45, 663-675. doi: 10.1007/s12031-011-9637-9

Feiguin, F., Godena, V. K., Romano, G., D’Ambrogio, A., Klima, R., and Baralle, F. E. (2009). Depletion of TDP-43 affects Drosophila motoneurons terminal synapsis and locomotive behavior. FEBS Lett. 583, 1586-1592. doi: 10.1016/ j.febslet.2009.04.019

Fernández-Ayala, D. J. M., Chen, S., Kemppainen, E., O’Dell, K. M. C., and Jacobs, H. T. (2010). Gene expression in a Drosophila model of mitochondrial disease. PLoS One 5:e8549. doi: 10.1371/journal.pone.0008549

Ferrante, R. J., Browne, S. E., Shinobu, L. A., Bowling, A. C., Baik, M. J., MacGarvey, U., et al. (1997). Evidence of increased oxidative damage in both sporadic and familial amyotrophic lateral sclerosis. J. Neurochem. 69, 2064-2074. doi: 10.1046/j.1471-4159.1997.69052064.x

Ferrari, R., Kapogiannis, D., Huey, E. D., and Momeni, P. (2011). FTD and ALS: a tale of two diseases. Curr. Alzheimer Res. 8, 273-294. doi: 10.2174/ 156720511795563700

Ferri, A., Fiorenzo, P., Nencini, M., Cozzolino, M., Pesaresi, M. G., Valle, C., et al. (2010). Glutaredoxin 2 prevents aggregation of mutant SOD1 in mitochondria and abolishes its toxicity. Hum. Mol. Genet. 19, 4529-4542. doi: 10.1093/hmg/ ddq 383

Fischer, J. A., Giniger, E., Maniatis, T., and Ptashne, M. (1988). GAL4 activates transcription in Drosophila. Nature 332, 853-856. doi: 10.1038/332853a0

Fleming, R. J. (1998). Structural conservation of Notch receptors and ligands. Semin. Cell Dev. Biol. 9, 599-607. doi: 10.1006/scdb.1998. 0260

Frazier, A. E., and Thorburn, D. R. (2012). "Biochemical analyses of the electron transport chain complexes by spectrophotometry," in Mitochondrial Disorders: Biochemical and Molecular Analysis, ed. L. J. C. Wong (Totowa: Humana Press), 49-62. doi: 10.1007/978-1-61779-504-6_4
Freibaum, B. D., Lu, Y., Lopez-Gonzalez, R., Kim, N. C., Almeida, S., Lee, K.-H., et al. (2015). GGGGCC repeat expansion in C9orf72 compromises nucleocytoplasmic transport. Nature 525, 129-133. doi: 10.1038/nature14974

Freischmidt, A., Wieland, T., Richter, B., Ruf, W., Schaeffer, V., Müller, K., et al. (2015). Haploinsufficiency of TBK1 causes familial ALS and fronto-temporal dementia. Nat. Neurosci. 18, 631-636. doi: 10.1038/nn.4000

Gallart-Palau, X., Ng, C. H., Ribera, J., Sze, S. K., and Lim, K. L. (2016). Drosophila expressing human SOD1 successfully recapitulates mitochondrial phenotypic features of familial amyotrophic lateral sclerosis. Neurosci. Lett. 624, 47-52. doi: 10.1016/j.neulet.2016.05.006

Garesse, R., and Kaguni, L. S. (2005). A drosophila model of mitochondrial DNA replication: proteins, genes and regulation. IUBMB Life 57, 555-561. doi: $10.1080 / 15216540500215572$

Gendron, T. F., Belzil, V. V., Zhang, Y. J., and Petrucelli, L. (2014). Mechanisms of toxicity in C9FTLD/ALS. Acta Neuropathol. 127, 359-376. doi: 10.1007/ s00401-013-1237-z

Genin, E. C., Bannwarth, S., Lespinasse, F., Ortega-Vila, B., Fragaki, K., Itoh, K., et al. (2018). Loss of MICOS complex integrity and mitochondrial damage, but not TDP-43 mitochondrial localisation, are likely associated with severity of CHCHD10-related diseases. Neurobiol. Dis. 119, 159-171. doi: 10.1016/j.nbd. 2018.07.027

Giordana, M. T., Piccinini, M., Grifoni, S., De Marco, G., Vercellino, M., Magistrello, M., et al. (2010). TDP-43 redistribution is an early event in sporadic amyotrophic lateral sclerosis. Brain Pathol. 20, 351-360. doi: 10.1111/j.17503639.2009.00284.x

Greaves, C. V., and Rohrer, J. D. (2019). An update on genetic frontotemporal dementia. J. Neurol. 266, 2075-2086. doi: 10.1007/s00415-019-09363-4

Greenspan, R. J. (1997). Fly Pushing: the Theory and Practice of Drosophila Genetics. New York: Cold Spring Harbour Laboratory Press.

Greenway, M. J., Andersen, P. M., Russ, C., Ennis, S., Cashman, S., Donaghy, C., et al. (2006). ANG mutations segregate with familial and "sporadic" amyotrophic lateral sclerosis. Nat. Genet. 38, 411-413. doi: 10.1038/ng1742

Gregory, J. M., Fagegaltier, D., Phatnani, H., and Harms, M. B. (2020). Genetics of amyotrophic lateral sclerosis. Curr. Genet. Med. Rep. 8, 121-131. doi: 10.1007/ s40142-020-00194-8

Guo, C., Sun, L., Chen, X., and Zhang, D. (2013). Oxidative stress, mitochondrial damage and neurodegenerative diseases. Neural Regen. Res. 8, 2003-2014. doi: 10.3969/j.issn.1673-5374.2013.21.009

Hales, K. G., and Fuller, M. T. (1997). Developmentally regulated mitochondrial fusion mediated by a conserved, novel, predicted GTPase. Cell 90, 121-129. doi: $10.1016 / \mathrm{s} 0092-8674(00) 80319-0$

Hardy, J., and Rogaeva, E. (2014). Motor neuron disease and frontotemporal dementia: Sometimes related, sometimes not. Exp. Neurol. 262, 75-83. doi: 10.1016/j.expneurol.2013.11.006

Higgins, C. M. J., Jung, C., and Xu, Z. (2003). ALS-associated mutant SOD1G93A causes mitochondrial vacuolation by expansion of the intermembrane space and by involvement of SOD1 aggregation and peroxisomes. BMC Neurosci. 4:16. doi: 10.1186/1471-2202-4-16

Hirth, F. (2010). Drosophila melanogaster in the study of human neurodegeneration. CNS Neurol. Disord. Drug Targets 9, 504-523. doi: 10.2174/187152710791556104

Holley, S. A., Jackson, P. D., Sasai, Y., Lu, B., De Robertis, E. M., Hoffmann, F. M., et al. (1995). A conserved system for dorsal-ventral patterning in insects and vertebrates involving sog and chordin. Nature 376, 249-253. doi: 10.1038/ $376249 \mathrm{a} 0$

Horan, M. P., Pichaud, N., and Ballard, J. W. O. (2012). Review: quantifying mitochondrial dysfunction in complex diseases of aging. J. Gerontol. Ser. A Biol. Sci. Med. Sci. 67, 1022-1035. doi: 10.1093/gerona/glr263

Huang, E. J., Zhang, J., Geser, F., Trojanowski, J. Q., Strober, J. B., Dickson, D. W., et al. (2010). Extensive FUS-immunoreactive pathology in juvenile amyotrophic lateral sclerosis with basophilic inclusions. Brain Pathol. 20, 1069-1076. doi: 10.1111/j.1750-3639.2010.00413.x

Hutton, M., Lendon, C. L., Rizzu, P., Baker, M., Froelich, S., Houlden, H., et al. (1998). Association of missense and 5'-splice-site mutations in tau with the inherited dementia FTDP-17. Nature 393, 702-705. doi: 10.1038/31508

Hwang, R.-D., Wiemerslage, L., LaBreck, C. J., Khan, M., Kannan, K., Wang, X., et al. (2014). The neuroprotective effect of human uncoupling protein 2 (hUCP2) requires cAMP-dependent protein kinase in a toxin model of 
Parkinson's disease. Neurobiol. Dis. 69, 180-191. doi: 10.1016/j.nbd.2014.05. 032

Inagaki, H. K., Kamikouchi, A., and Ito, K. (2010). Methods for quantifying simple gravity sensing in Drosophila melanogaster. Nat. Protoc. 5, 20-25. doi: 10.1038/ nprot.2009.196

Jaarsma, D., Rognoni, F., Van Duijn, W., Verspaget, H. W., Haasdijk, E. D., and Holstege, J. C. (2001). CuZn superoxide dismutase (SOD1) accumulates in vacuolated mitochondria in transgenic mice expressing amyotrophic lateral sclerosis-linked SOD1 mutations. Acta Neuropathol. 102, 293-305. doi: 10. 1007/s004010100399

Jackson, G. R., Salecker, I., Dong, X., Yao, X., Arnheim, N., Faber, P. W., et al. (1998). Polyglutamine-expanded human huntingtin transgenes induce degeneration of Drosophila photoreceptor neurons. Neuron 21, 633-642. doi: 10.1016/S0896-6273(00)80573-5

Jacobs, H. T., Fernández-Ayala, D. J. M., Manjiry, S., Kemppainen, E., Toivonen, J. M., and O'Dell, K. M. (2004). Mitochondrial disease in flies. Biochim. Biophys. Acta Bioenerg. 1659, 190-196. doi: 10.1016/j.bbabio.2004.07.004

Janssen, R. C., and Boyle, K. E. (2019). Microplate assays for spectrophotometric measurement of mitochondrial enzyme activity. Methods Mol. Biol. 1978, 355-368. doi: 10.1007/978-1-4939-9236-2_22

Jenett, A., Rubin, G. M., Ngo, T.-T. B., Shepherd, D., Murphy, C., Dionne, H., et al. (2012). A GAL4-driver line resource for Drosophila neurobiology. Cell Rep. 2, 991-1001. doi: 10.1016/j.celrep.2012.09.011

Johnson, J. O., Mandrioli, J., Benatar, M., Abramzon, Y., Van Deerlin, V. M., Trojanowski, J. Q., et al. (2010). Exome Sequencing Reveals VCP Mutations as a Cause of Familial ALS. Neuron 68, 857-864. doi: 10.1016/j.neuron.2010.11.036

Johnson, J. O., Pioro, E. P., Boehringer, A., Chia, R., Feit, H., Renton, A. E., et al. (2014). Mutations in the Matrin 3 gene cause familial amyotrophic lateral sclerosis. Nat. Neurosci. 17, 664-666. doi: 10.1038/nn.3688

Kann, O., and Kovács, R. (2007). Mitochondria and neuronal activity. Am. J. Physiol. Physiol. 292, C641-C657. doi: 10.1152/ajpcell.00222.2006

Kasture, A. S., Hummel, T., Sucic, S., and Freissmuth, M. (2018). Big lessons from tiny flies: drosophila melanogaster as a model to explore dysfunction of dopaminergic and serotonergic neurotransmitter systems. Int. J. Mol. Sci. 19:1788. doi: 10.3390/ijms19061788

Khalil, B., Cabirol-Pol, M. J., Miguel, L., Whitworth, A. J., Lecourtois, M., and Liévens, J. C. (2017). Enhancing Mitofusin/Marf ameliorates neuromuscular dysfunction in Drosophila models of TDP-43 proteinopathies. Neurobiol. Aging 54, 71-83. doi: 10.1016/j.neurobiolaging.2017.02.016

Kim, H. J., and Taylor, J. P. (2017). Lost in transportation: nucleocytoplasmic transport defects in ALS and other neurodegenerative diseases. Neuron 96, 285-297. doi: 10.1016/j.neuron.2017.07.029

Kim, J., Koo, B.-K., and Knoblich, J. A. (2020). Human organoids: model systems for human biology and medicine. Nat. Rev. Mol. Cell Biol. 21, 571-584. doi: 10.1038/s41580-020-0259-3

King, A. E., Woodhouse, A., Kirkcaldie, M. T. K., and Vickers, J. C. (2016). Excitotoxicity in ALS: overstimulation, or overreaction? Exp. Neurol. 275, 162-171. doi: 10.1016/j.expneurol.2015.09.019

Kong, J., and Xu, Z. (1998). Massive mitochondrial degeneration in motor neurons triggers the onset of amyotrophic lateral sclerosis in mice expressing a mutant SOD1. J. Neurosci. 18, 3241-3250. doi: 10.1523/jneurosci.18-09-03241.1998

Kwiatkowski, T. J., Bosco, D. A., LeClerc, A. L., Tamrazian, E., Vanderburg, C. R., Russ, C., et al. (2009). Mutations in the FUS/TLS gene on chromosome 16 cause familial amyotrophic lateral sclerosis. Science 323, 1205-1208. doi: 10.1126/ science. 1166066

Lacomblez, L., Bensimon, G., Leigh, P. N., Guillet, P., and Meininger, V. (1996). Dose-ranging study of riluzole in amyotrophic lateral sclerosis. Amyotrophic lateral sclerosis/Riluzole Study Group II. Lancet 347, 1425-1431. doi: 10.1016/ s0140-6736(96)91680-3

Lagier-Tourenne, C., Polymenidou, M., and Cleveland, D. W. (2010). TDP-43 and FUS/TLS: emerging roles in RNA processing and neurodegeneration. Hum. Mol. Genet. 19, R46-R64. doi: 10.1093/hmg/ddq137

Lamb, R., Rohrer, J. D., Real, R., Lubbe, S. J., Waite, A. J., Blake, D. J., et al. (2019). A novel TBK1 mutation in a family with diverse frontotemporal dementia spectrum disorders. Cold Spring Harb. Mol. Case Stud. 5:a003913. doi: 10.1101/ mcs.a003913

Le Ber, I., Camuzat, A., Guerreiro, R., Bouya-Ahmed, K., Bras, J., Nicolas, G., et al. (2013). SQSTM1 Mutations in french patients with frontotemporal dementia or frontotemporal dementia with amyotrophic lateral sclerosis. JAMA Neurol. 70, 1403-1410. doi: 10.1001/jamaneurol.2013.3849

Lehmer, C., Schludi, M. H., Ransom, L., Greiling, J., Junghänel, M., Exner, N., et al. (2018). A novel CHCHD10 mutation implicates a Mia40-dependent mitochondrial import deficit in ALS. EMBO Mol. Med. 10:e8558. doi: 10.15252/ emmm.201708558

Lenz, S., Karsten, P., Schulz, J. B., and Voigt, A. (2013). Drosophila as a screening tool to study human neurodegenerative diseases. J. Neurochem. 127, 453-460. doi: 10.1111/jnc. 12446

Lewis, O. L., Farr, C. L., and Kaguni, L. S. (1995). Drosophila melanogaster mitochondrial DNA: completion of the nucleotide sequence and evolutionary comparisons. Insect Mol. Biol. 4, 263-278. doi: 10.1111/j.1365-2583.1995. tb00032.x

Li, S., Wu, Z., Li, Y., Tantray, I., De Stefani, D., Mattarei, A., et al. (2020). Altered MICOS Morphology and Mitochondrial Ion Homeostasis Contribute to Poly(GR) Toxicity Associated with C9-ALS/FTD. Cell Rep. 32:107989. doi: 10.1016/j.celrep.2020.107989

Lin, M.-J., Cheng, C.-W., and Shen, C.-K. J. (2011). Neuronal function and dysfunction of Drosophila dTDP. PLoS One 6:e20371. doi: 10.1371/journal. pone. 0020371

Ling, S. C., Polymenidou, M., and Cleveland, D. W. (2013). Converging mechanisms in als and FTD: disrupted RNA and protein homeostasis. Neuron 79, 416-438. doi: 10.1016/j.neuron.2013.07.033

Liscic, R. M., Alberici, A., Cairns, N. J., Romano, M., and Buratti, E. (2020). From basic research to the clinic: innovative therapies for ALS and FTD in the pipeline. Mol. Neurodegener. 15:31. doi: 10.1186/s13024-020-00373-9

Liu, R., Li, B., Flanagan, S. W., Oberley, L. W., Gozal, D., and Qiu, M. (2002). Increased mitochondrial antioxidative activity or decreased oxygen free radical propagation prevent mutant SOD1-mediated motor neuron cell death and increase amyotrophic lateral sclerosis-like transgenic mouse survival. J. Neurochem. 80, 488-500. doi: 10.1046/j.0022-3042.2001.00720.x

Liu, W., Yamashita, T., Tian, F., Morimoto, N., Ikeda, Y., Deguchi, K., et al. (2013). Mitochondrial fusion and fission proteins expression dynamically change in a murine model of amyotrophic lateral sclerosis. Curr. Neurovasc. Res. 10, 222-230. doi: 10.2174/15672026113109990060

Lopez-Gonzalez, R., Lu, Y., Gendron, T. F., Karydas, A., Tran, H., Yang, D., et al. (2016). Poly(GR) in C9ORF72-Related ALS/FTD compromises mitochondrial function and increases oxidative stress and DNA Damage in iPSC-derived motor neurons. Neuron 92, 383-391. doi: 10.1016/j.neuron.2016. 09.015

Lu, Y., Ferris, J., and Gao, F. B. (2009). Frontotemporal dementia and amyotrophic lateral sclerosis-associated disease protein TDP-43 promotes dendritic branching. Mol. Brain 2, 1-10. doi: 10.1186/1756-66062-30

Luan, H., Diao, F., Scott, R. L., and White, B. H. (2020). The drosophila split Gal4 system for neural circuit mapping. Front. Neural Circ. 14:603397. doi: 10.3389/fncir.2020.603397

Lue, N. F., Chasman, D. I., Buchman, A. R., and Kornberg, R. D. (1987). Interaction of GAL4 and GAL80 gene regulatory proteins in vitro. Mol. Cell. Biol. 7, 3446-3451. doi: 10.1128/mcb.7.10.3446-3451.1987

Lutas, A., Wahlmark, C. J., Acharjee, S., and Kawasaki, F. (2012). Genetic analysis in drosophila reveals a role for the mitochondrial protein P32 in synaptic transmission. G3 (Bethesda) 2, 59-69. doi: 10.1534/g3.111.001586

Mackenzie, I. R., Nicholson, A. M., Sarkar, M., Messing, J., Purice, M. D., Pottier, C., et al. (2017). TIAl Mutations in amyotrophic lateral sclerosis and frontotemporal dementia promote phase separation and alter stress granule dynamics. Neuron 95, 808-816.e9. doi: 10.1016/j.neuron.2017. 07.025

Mackenzie, I. R., Rademakers, R., and Neumann, M. (2010). TDP-43 and FUS in amyotrophic lateral sclerosis and frontotemporal dementia. Lancet Neurol. 9, 995-1007. doi: 10.1016/S1474-4422(10)70195-2

Majounie, E., Renton, A. E., Mok, K., Dopper, E. G. P., Waite, A., Rollinson, S., et al. (2012). Frequency of the C9orf72 hexanucleotide repeat expansion in patients with amyotrophic lateral sclerosis and frontotemporal dementia: a cross-sectional study. Lancet Neurol. 11, 323-330. doi: 10.1016/S1474-4422(12) 70043-1

Manjaly, Z. R., Scott, K. M., Abhinav, K., Wijesekera, L., Ganesalingam, J., Goldstein, L. H., et al. (2010). The sex ratio in amyotrophic lateral sclerosis: 
a population based study. Amyotroph. Lateral Scler. 11, 439-442. doi: 10.3109/ 17482961003610853

Mariottini, P., Shah, Z. H., Toivonen, J. M., Bagni, C., Spelbrink, J. N., Amaldi, F., et al. (1999). Expression of the gene for mitoribosomal protein S12 is controlled in human cells at the levels of transcription, RNA splicing, and translation. J. Biol. Chem. 274, 31853-31862. doi: 10.1074/jbc.274.45.31 853

Martinaud, O., Laquerrière, A., Guyant-Maréchal, L., Ahtoy, P., Vera, P., Sergeant, N., et al. (2005). Frontotemporal dementia, motor neuron disease and tauopathy: clinical and neuropathological study in a family. Acta Neuropathol. 110, 84-92. doi: 10.1007/s00401-005-1028-2

Maruyama, H., Morino, H., Ito, H., Izumi, Y., Kato, H., Watanabe, Y., et al. (2010). Mutations of optineurin in amyotrophic lateral sclerosis. Nature 465, 223-226. doi: $10.1038 /$ nature 08971

Mateen, F. J., Carone, M., and Sorenson, E. J. (2010). Patients who survive 5 years or more with ALS in Olmsted County, 1925-2004. J. Neurol. Neurosurg. Psychiatry 81, 1144-1146. doi: 10.1136/jnnp.2009.201251

Mattiazzi, M., D’Aurelio, M., Gajewski, C. D., Martushova, K., Kiaei, M., Flint Beal, M., et al. (2002). Mutated human SOD1 causes dysfunction of oxidative phosphorylation in mitochondria of transgenic mice. J. Biol. Chem. 277, 2962629633. doi: $10.1074 /$ jbc.M203065200

McGurk, L., Berson, A., and Bonini, N. M. (2015). Drosophila as an in vivo model for human neurodegenerative disease. Genetics 201, 377-402. doi: 10.1534/ genetics.115.179457

Mehta, A. R., Gregory, J. M., Dando, O., Carter, R. N., Burr, K., Nanda, J., et al. (2021). Mitochondrial bioenergetic deficits in C9orf72 amyotrophic lateral sclerosis motor neurons cause dysfunctional axonal homeostasis. Acta Neuropathol. 141, 257-279. doi: 10.1007/s00401-020-02252-5

Mejzini, R., Flynn, L. L., Pitout, I. L., Fletcher, S., Wilton, S. D., and Akkari, P. A. (2019). ALS genetics, mechanisms, and therapeutics : where are we now? Front Neurosci. 13:1310. doi: 10.3389/fnins.2019.01310

Méndez-López, I., Sancho-Bielsa, F. J., Engel, T., García, A. G., and Padín, J. F. (2021). Progressive Mitochondrial SOD $1^{G 93 A}$ accumulation causes severe structural, metabolic and functional aberrations through opal down-regulation in a mouse model of amyotrophic lateral sclerosis. Int. J. Mol. Sci. 22:8194. doi: 10.3390/ijms22158194

Menzies, F. M., Yenisetti, S. C., and Min, K.-T. (2005). Roles of Drosophila DJ1 in survival of dopaminergic neurons and oxidative stress. Curr. Biol. 15, 1578-1582. doi: 10.1016/j.cub.2005.07.036

Mercy, L., Hodges, J. R., Dawson, K., Barker, R. A., and Brayne, C. (2008). Incidence of early-onset dementias in Cambridgeshire, United Kingdom. Neurology 71, 1496-1499. doi: 10.1212/01.wnl.0000334277.16896.fa

Meulener, M., Whitworth, A. J., Armstrong-Gold, C. E., Rizzu, P., Heutink, P., Wes, P. D., et al. (2005). Drosophila DJ-1 mutants are selectively sensitive to environmental toxins associated with Parkinson's disease. Curr. Biol. 15, 1572-1577. doi: 10.1016/j.cub.2005.07.064

Millecamps, S., Salachas, F., Cazeneuve, C., Gordon, P., Bricka, B., Camuzat, A. et al. (2010). SOD1, ANG, VAPB, TARDBP, and FUS mutations in familial amyotrophic lateral sclerosis: genotype-phenotype correlations. J. Med. Genet. 47, 554-560. doi: 10.1136/jmg.2010.077180

Millul, A., Beghi, E., Logroscino, G., Micheli, A., Vitelli, E., and Zardi, A. (2005). Survival of patients with amyotrophic lateral sclerosis in a population-based registry. Neuroepidemiology 25, 114-119. doi: 10.1159/000086353

Mizielinska, S., Grönke, S., Niccoli, T., Ridler, C. E., Clayton, E. L., Devoy, A., et al. (2014). C9orf72 repeat expansions cause neurodegeneration in Drosophila through arginine-rich proteins. Science 345, 1192-1195. doi: 10.1126/science. 1256800

Mockett, R. J., Radyuk, S. N., Benes, J. J., Orr, W. C., and Sohal, R. S. (2003). Phenotypic effects of familial amyotrophic lateral sclerosis Sod alleles in transgenic Drosophila. Proc. Natl. Acad. Sci. U. S. A. 100, 301-306. doi: 10. 1073/pnas.0136976100

Mohr, S. E., Hu, Y., Kim, K., Housden, B. E., and Perrimon, N. (2014). Resources for functional genomics studies in Drosophila melanogaster. Genetics 197, 1-18. doi: 10.1534/genetics.113.154344

Mori, K., Arzberger, T., Grässer, F. A., Gijselinck, I., May, S., Rentzsch, K., et al. (2013). Bidirectional transcripts of the expanded C9orf72 hexanucleotide repeat are translated into aggregating dipeptide repeat proteins. Acta Neuropathol. 126, 881-893. doi: 10.1007/s00401-013-1189-3
Morris, O., Deng, H., Tam, C., and Jasper, H. (2020). Warburg-like metabolic reprogramming in aging intestinal stem cells contributes to tissue hyperplasia. Cell Rep. 33:108423. doi: 10.1016/j.celrep.2020.108423

Münch, C., Rosenbohm, A., Sperfeld, A.-D., Uttner, I., Reske, S., Krause, B. J., et al. (2005). Heterozygous R1101K mutation of the DCTN1 gene in a family with ALS and FTD. Ann. Neurol. 58, 777-780. doi: 10.1002/ana.20631

Münch, C., Sedlmeier, R., Meyer, T., Homberg, V., Sperfeld, A. D., Kurt, A., et al. (2004). Point mutations of the p150 subunit of dynactin (DCTN1) gene in ALS. Neurology 63, 724-726. doi: 10.1212/01.wnl.0000134608.83927.b1

Nakaya, T., and Maragkakis, M. (2018). Amyotrophic Lateral Sclerosis associated FUS mutation shortens mitochondria and induces neurotoxicity. Sci. Rep. 8:15575. doi: 10.1038/s41598-018-33964-0

Neumann, M., Sampathu, D. M., Kwong, L. K., Truax, A. C., Micsenyi, M. C., Chou, T. T., et al. (2006). Ubiquitinated TDP-43 in frontotemporal lobar degeneration and amyotrophic lateral sclerosis. Science 314, 130-133. doi: $10.1126 /$ science. 1134108

Nguyen, H. P., Van Broeckhoven, C., and van der Zee, J. (2018). ALS Genes in the Genomic Era and their Implications for FTD. Trends Genet. 34, 404-423. doi: 10.1016/j.tig.2018.03.001

Nicholson, L., Singh, G. K., Osterwalder, T., Roman, G. W., Davis, R. L., and Keshishian, H. (2008). Spatial and temporal control of gene expression in Drosophila using the inducible GeneSwitch GAL4 system. I. Screen for larval nervous system drivers. Genetics 178, 215-234. doi: 10.1534/genetics.107. 081968

Nishimura, A. L., Mitne-Neto, M., Silva, H. C. A., Richieri-Costa, A., Middleton, S., Cascio, D., et al. (2004). A mutation in the vesicle-trafficking protein VAPB causes late-onset spinal muscular atrophy and amyotrophic lateral sclerosis. Am. J. Hum. Genet. 75, 822-831. doi: 10.1086/425287

Onesto, E., Colombrita, C., Gumina, V., Borghi, M. O., Dusi, S., Doretti, A., et al. (2016). Gene-specific mitochondria dysfunctions in human TARDBP and C9ORF72 fibroblasts. Acta Neuropathol. Commun. 4:47. doi: 10.1186/s40478016-0316-5

Onyike, C. U., and Diehl-Schmid, J. (2013). The epidemiology of frontotemporal dementia. Int. Rev. Psychiatry 25, 130-137. doi: 10.3109/09540261.2013.776523

Orr, H. T. (2011). FTD and ALS: genetic ties that bind. Neuron 72, 189-190. doi: 10.1016/j.neuron.2011.10.001

Orsini, M., Oliveira, A. B., Nascimento, O. J. M., Reis, C. H. M., Leite, M. A. A., de Souza, J. A., et al. (2015). Amyotrophic lateral sclerosis: new perpectives and update. Neurol. Int. 7, 39-47. doi: 10.4081/ni.2015.5885

Osterwalder, T., Yoon, K. S., White, B. H., and Keshishian, H. (2001). A conditional tissue-specific transgene expression system using inducible GAL4. Proc. Natl. Acad. Sci. U. S. A. 98, 12596-12601. doi: 10.1073/pnas.221303298

Pandya, R. S., Zhu, H., Li, W., Bowser, R., Friedlander, R. M., and Wang, X. (2013). Therapeutic neuroprotective agents for amyotrophic lateral sclerosis. Cell. Mol. Life Sci. 70, 4729-4745. doi: 10.1007/s00018-013-1415-0

Pardo, C. A., Xu, Z., Borchelt, D. R., Price, D. L., Sisodia, S. S., and Cleveland, D. W. (1995). Superoxide dismutase is an abundant component in cell bodies, dendrites, and axons of motor neurons and in a subset of other neurons. Proc. Natl. Acad. Sci. U. S. A. 92, 954-958. doi: 10.1073/pnas.92.4.954

Park, J., Lee, S. B., Lee, S., Kim, Y., Song, S., Kim, S., et al. (2006). Mitochondrial dysfunction in Drosophila PINK1 mutants is complemented by parkin. Nature 441, 1157-1161. doi: 10.1038/nature04788

Parkinson, N., Ince, P. G., Smith, M. O., Highley, R., Skibinski, G., Andersen, P. M., et al. (2006). ALS phenotypes with mutations in CHMP2B (charged multivesicular body protein 2B). Neurology 67, 1074-1077. doi: 10.1212/01.wnl. $0000231510.89311 .8 \mathrm{~b}$

Perkins, L. A., Holderbaum, L., Tao, R., Hu, Y., Sopko, R., McCall, K., et al. (2015). The transgenic RNAi project at harvard medical school: resources and validation. Genetics 201, 843-852. doi: 10.1534/genetics.115.180208

Perry, C. G., Kane, D. A., Lanza, I. R., and Neufer, P. D. (2013). Methods for assessing mitochondrial function in diabetes. Diabetes 62, 1041-1053. doi: $10.2337 / \mathrm{db} 12-1219$

Perry, S. W., Norman, J. P., Barbieri, J., Brown, E. B., and Gelbard, H. A. (2011). Mitochondrial membrane potential probes and the proton gradient: a practical usage guide. Biotechniques 50, 98-115. doi: 10.2144/000113610

Pfeiffenberger, C., Lear, B. C., Keegan, K. P., and Allada, R. (2010). Locomotor activity level monitoring using the Drosophila Activity Monitoring (DAM) System. Cold Spring Harb. Protoc. 2010:pdb.rot5518. doi: 10.1101/pdb.prot5518 
Pfeiffer, B. D., Jenett, A., Hammonds, A. S., Ngo, T.-T. B., Misra, S., Murphy, C., et al. (2008). Tools for neuroanatomy and neurogenetics in Drosophila. Proc. Natl. Acad. Sci. U. S. A. 105, 9715-9720. doi: 10.1073/pnas.0803697105

Piazza, N., and Wessells, R. J. (2011). Drosophila models of cardiac disease. Prog. Mol. Biol. Transl. Sci. 100, 155-210. doi: 10.1016/B978-0-12-384878-9.00005-4

Piper, M. D., and Partridge, L. (2016). Protocols to study aging in drosophila. Methods Mol. Biol. 1478, 291-302. doi: 10.1007/978-1-4939-6371-3_18

Piper, M. D., and Partridge, L. (2018). Drosophila as a model for ageing. Biochim. Biophys. Acta Mol. Basis Dis. 1864, 2707-2717. doi: 10.1016/j.bbadis.2017.09. 016

Pizzino, G., Irrera, N., Cucinotta, M., Pallio, G., Mannino, F., Arcoraci, V., et al. (2017). Oxidative stress: harms and benefits for human health. Oxid. Med. Cell. Longev. 2017:8416763. doi: 10.1155/2017/8416763

Poole, A. C., Thomas, R. E., Andrews, L. A., McBride, H. M., Whitworth, A. J., and Pallanck, L. J. (2008). The PINK1/Parkin pathway regulates mitochondrial morphology. Proc. Natl. Acad. Sci. U. S. A. 105, 1638-1643. doi: 10.1073/pnas. 0709336105

Pottier, C., Bieniek, K. F., Finch, N., van de Vorst, M., Baker, M., Perkersen, R., et al. (2015). Whole-genome sequencing reveals important role for TBK1 and OPTN mutations in frontotemporal lobar degeneration without motor neuron disease. Acta Neuropathol. 130, 77-92. doi: 10.1007/s00401-015-1436-x

Presley, A. D., Fuller, K. M., and Arriaga, E. A. (2003). MitoTracker Green labeling of mitochondrial proteins and their subsequent analysis by capillary electrophoresis with laser-induced fluorescence detection. J. Chromatogr. B Anal. Technol. Biomed. Life Sci. 793, 141-150. doi: 10.1016/s1570-0232(03) 00371-4

Puls, I., Jonnakuty, C., LaMonte, B. H., Holzbaur, E. L. F., Tokito, M., Mann, E., et al. (2003). Mutant dynactin in motor neuron disease. Nat. Genet. 33, 455-456. doi: $10.1038 /$ ng 1123

Rademakers, R., Neumann, M., and Mackenzie, I. R. (2012). Advances in understanding the molecular basis of frontotemporal dementia. Nat. Rev. Neurol. 8, 423-434. doi: 10.1038/nrneurol.2012.117

Rana, A., Oliveira, M. P., Khamoui, A. V., Aparicio, R., Rera, M., Rossiter, H. B., et al. (2017). Promoting Drp1-mediated mitochondrial fission in midlife prolongs healthy lifespan of Drosophila melanogaster. Nat. Commun. 8:448. doi: 10.1038/s41467-017-00525-4

Reiter, L. T., Potocki, L., Chien, S., Gribskov, M., and Bier, E. (2001). A systematic analysis of human disease-associated gene sequences in Drosophila melanogaster. Genome Res. 11, 1114-1125. doi: 10.1101/gr.169101

Renton, A. E., Majounie, E., Waite, A., Simón-Sánchez, J., Rollinson, S., Gibbs, J. R., et al. (2011). A hexanucleotide repeat expansion in C9ORF72 is the cause of chromosome 9p21-linked ALS-FTD. Neuron 72, 257-268. doi: 10.1016/j. neuron.2011.09.010

Riddle, R. D., Johnson, R. L., Laufer, E., and Tabin, C. (1993). Sonic hedgehog mediates the polarizing activity of the ZPA. Cell 75, 1401-1416. doi: 10.1016/ 0092-8674(93)90626-2

Rizzardini, M., Mangolini, A., Lupi, M., Ubezio, P., Bendotti, C., and Cantoni, L. (2005). Low levels of ALS-linked Cu/Zn superoxide dismutase increase the production of reactive oxygen species and cause mitochondrial damage and death in motor neuron-like cells. J. Neurol. Sci. 232, 95-103. doi: 10.1016/j. jns.2005.02.004

Roberts, S., and Speirs, V. (2017). Advances in the development of improved animal-free models for use in breast cancer biomedical research. Biophys. Rev. 9, 321-327. doi: 10.1007/s12551-017-0276-4

Roelofs, B. A., Ge, S. X., Studlack, P. E., and Polster, B. M. (2015). Low micromolar concentrations of the superoxide probe MitoSOX uncouple neural mitochondria and inhibit complex IV. Free Radic. Biol. Med. 86, 250-258. doi: 10.1016/j.freeradbiomed.2015.05.032

Romero-Garcia, S., and Prado-Garcia, H. (2019). Mitochondrial calcium: transport and modulation of cellular processes in homeostasis and cancer (Review). Int. J. Oncol. 54, 1155-1167. doi: 10.3892/ijo.2019.4696

Rosen, D. R., Siddiquet, T., Pattersont, D., Figlewicz, D. A., Ii, P. S., Hentatit, A., et al. (1993). Mutations in $\mathrm{Cu} / \mathrm{Zn}$ superoxide dismutase gene are associated with familial amyotrophic lateral sclerosis. Nature 362, 59-62.

Royden, C. S., Pirrotta, V., and Jan, L. Y. (1987). The tko locus, site of a behavioral mutation in D. melanogaster, codes for a protein homologous to prokaryotic ribosomal protein S12. Cell 51, 165-173. doi: 10.1016/0092-8674(87)90144-9
Rubino, E., Mancini, C., Boschi, S., Ferrero, P., Ferrone, M., Bianca, S., et al. (2019). ATXN2 intermediate repeat expansions influence the clinical phenotype in frontotemporal dementia. Neurobiol. Aging 73, 231.e7-231.e9. doi: 10.1016/j. neurobiolaging.2018.09.009

Şahin, A., Held, A., Bredvik, K., Major, P., Achilli, T.-M., Kerson, A. G., et al. (2017). Human SOD1 ALS mutations in a drosophila knock-in model cause severe phenotypes and reveal dosage-sensitive gain- and loss-of-function components. Genetics 205, 707-723. doi: 10.1534/genetics.116.190850

Salvatori, I., Ferri, A., Scaricamazza, S., Giovannelli, I., Serrano, A., Rossi, S., et al. (2018). Differential toxicity of TAR DNA-binding protein 43 isoforms depends on their submitochondrial localization in neuronal cells. J. Neurochem. 146, 585-597. doi: 10.1111/jnc.14465

Sasaki, S., and Iwata, M. (2007). Mitochondrial alterations in the spinal cord of patients with sporadic amyotrophic lateral sclerosis. J. Neuropathol. Exp. Neurol. 66, 10-16. doi: 10.1097/nen.0b013e31802c396b

Sasaki, S., Warita, H., Murakami, T., Abe, K., and Iwata, M. (2004). Ultrastructural study of mitochondria in the spinal cord of transgenic mice with a G93A mutant SOD1 gene. Acta Neuropathol. 107, 461-474. doi: 10.1007/s00401-004-0837-z

Schieber, M., and Chandel, N. S. (2014). ROS function in redox signaling and oxidative stress. Curr. Biol. 24, R453-R462. doi: 10.1016/j.cub.2014.03.034

Seager, R., Lee, L., Henley, J. M., and Wilkinson, K. A. (2020). Mechanisms and roles of mitochondrial localisation and dynamics in neuronal function. Neuronal Signal. 4:NS20200008. doi: 10.1042/NS20200008

Selman, C., Lingard, S., Choudhury, A. I., Batterham, R. L., Claret, M., Clements, M., et al. (2008). Evidence for lifespan extension and delayed age-related biomarkers in insulin receptor substrate 1 null mice. FASEB J. Off. Publ. Fed. Am. Soc. Exp. Biol. 22, 807-818. doi: 10.1096/fj.07-9261com

Seltman, R. E., and Matthews, B. R. (2012). Frontotemporal lobar degeneration: epidemiology, pathology, diagnosis and management. CNS Drugs 26, 841-870. doi: 10.2165/11640070-000000000-00000

Sen, A., and Cox, R. T. (2017). "Chapter one - Fly models of human diseases: drosophila as a model for understanding human mitochondrial mutations and disease," in Fly Models of Human Diseases, ed. L. Pick (Cambridge: Academic Press), 1-27. doi: 10.1016/bs.ctdb.2016.07.001

Shahheydari, H., Ragagnin, A., Walker, A. K., Toth, R. P., Vidal, M., Jagaraj, C. J., et al. (2017). Protein quality control and the amyotrophic lateral sclerosis/frontotemporal dementia continuum. Front. Mol. Neurosci. 10:119. doi: 10.3389/fnmol.2017.00119

Shaw, C. E., Enayat, Z. E., Chioza, B. A., Al-Chalabi, A., Radunovic, A., Powell, J. F., et al. (1998). Mutations in all five exons of SOD-1 may cause ALS. Ann. Neurol. 43, 390-394. doi: 10.1002/ana.410430319

Shi, K. Y., Mori, E., Nizami, Z. F., Lin, Y., Kato, M., Xiang, S., et al. (2017). Toxic PR(n) poly-dipeptides encoded by the C9orf72 repeat expansion block nuclear import and export. Proc. Natl. Acad. Sci. U. S. A. 114, E1111-E1117. doi: 10.1073/pnas.1620293114

Shibata, N., Nagai, R., Uchida, K., Horiuchi, S., Yamada, S., Hirano, A., et al. (2001). Morphological evidence for lipid peroxidation and protein glycoxidation in spinal cords from sporadic amyotrophic lateral sclerosis patients. Brain Res. 917 , 97-104. doi: 10.1016/S0006-8993(01)02926-2

Sivandzade, F., Bhalerao, A., and Cucullo, L. (2019). Analysis of the mitochondrial membrane potential using the cationic JC-1 dye as a sensitive fluorescent probe. Bio-Protocol. 9:e3128. doi: 10.21769/bioprotoc.3128

Skibinski, G., Parkinson, N. J., Brown, J. M., Chakrabarti, L., Lloyd, S. L., Hummerich, H., et al. (2005). Mutations in the endosomal ESCRTIII-complex subunit CHMP2B in frontotemporal dementia. Nat. Genet. 37, 806-808. doi: $10.1038 /$ ng 1609

Smith, B. N., Ticozzi, N., Fallini, C., Gkazi, A. S., Topp, S., Kenna, K. P., et al. (2014). Exome-wide rare variant analysis identifies TUBA4A mutations associated with familial ALS. Neuron 84, 324-331. doi: 10.1016/j.neuron.2014.09. 027

Smith, E. F., Shaw, P. J., and De Vos, K. J. (2019). The role of mitochondria in amyotrophic lateral sclerosis. Neurosci. Lett. 710:132933. doi: 10.1016/j.neulet. 2017.06.052

Sofola, O., Kerr, F., Rogers, I., Killick, R., Augustin, H., Gandy, C., et al. (2010). Inhibition of GSK-3 ameliorates Abeta pathology in an adult-onset Drosophila model of Alzheimer's disease. PLoS Genet. 6:e1001087. doi: 10.1371/journal. pgen.1001087 
Song, J., and Tanouye, M. A. (2008). From bench to drug: human seizure modeling using Drosophila. Prog. Neurobiol. 84, 182-191. doi: 10.1016/j.pneurobio.2007. 10.006

St Johnston, D. (2002). The art and design of genetic screens: drosophila melanogaster. Nat. Rev. Genet. 3, 176-188. doi: 10.1038/nrg751

Stoica, R., De Vos, K. J., Paillusson, S., Mueller, S., Sancho, R. M., Lau, K.-F., et al. (2014). ER-mitochondria associations are regulated by the VAPB-PTPIP51 interaction and are disrupted by ALS/FTD-associated TDP-43. Nat. Commun. 5:3996. doi: $10.1038 /$ ncomms4996

Stolow, D. T., and Haynes, S. R. (1995). Cabeza, a Drosophila gene encoding a novel RNA binding protein, shares homology with EWS and TLS, two genes involved in human sarcoma formation. Nucleic Acids Res. 23, 835-843. doi: 10.1093/nar/23.5.835

Stork, T., Bernardos, R., and Freeman, M. R. (2012). Analysis of glial cell development and function in Drosophila. Cold Spring Harb. Protoc. 7, 1-17. doi: $10.1101 / \mathrm{pdb}$. top067587

Straub, I. R., Weraarpachai, W., and Shoubridge, E. A. (2021). Multi-OMICS study of a CHCHD10 variant causing ALS demonstrates metabolic rewiring and activation of endoplasmic reticulum and mitochondrial unfolded protein responses. Hum. Mol. Genet. 30, 687-705. doi: 10.1093/hmg/ddab078

Sun, Y., Curle, A. J., Haider, A. M., and Balmus, G. (2020). The role of DNA damage response in amyotrophic lateral sclerosis. Essays Biochem. 64, 847-861. doi: 10.1042/EBC20200002

Synofzik, M., Maetzler, W., Grehl, T., Prudlo, J., vom Hagen, J. M., Haack, T., et al. (2012). Screening in ALS and FTD patients reveals 3 novel UBQLN2 mutations outside the PXX domain and a pure FTD phenotype. Neurobiol. Aging 33, 2949.e13-7. doi: 10.1016/j.neurobiolaging.2012.07.002

Tafuri, F., Ronchi, D., Magri, F., Comi, G. P., and Corti, S. (2015). SOD1 misplacing and mitochondrial dysfunction in amyotrophic lateral sclerosis pathogenesis. Front. Cell. Neurosci. 9:336. doi: 10.3389/fncel.2015.00336

Tam, V., Patel, N., Turcotte, M., Bossé, Y., Paré, G., and Meyre, D. (2019). Benefits and limitations of genome-wide association studies. Nat. Rev. Genet. 20, 467-484. doi: 10.1038/s41576-019-0127-1

Tao, Z., Wang, H., Xia, Q., Li, K., Li, K., Jiang, X., et al. (2015). Nucleolar stress and impaired stress granule formation contribute to C9orf72 RAN translationinduced cytotoxicity. Hum. Mol. Genet. 24, 2426-2441. doi: 10.1093/hmg/ ddv005

Tatar, M., Kopelman, A., Epstein, D., Tu, M. P., Yin, C. M., and Garofalo, R. S. (2001). A mutant Drosophila insulin receptor homolog that extends life-span and impairs neuroendocrine function. Science 292, 107-110. doi: 10.1126/ science. 1057987

Thaker, H. M., and Kankel, D. R. (1992). Mosaic analysis gives an estimate of the extent of genomic involvement in the development of the visual system in Drosophila melanogaster. Genetics 131, 883-894. doi: 10.1093/genetics/131.4. 883

Toivonen, J. M., O’Dell, K. M., Petit, N., Irvine, S. C., Knight, G. K., Lehtonen, M., et al. (2001). Technical knockout, a Drosophila model of mitochondrial deafness. Genetics 159, 241-254. doi: 10.1093/genetics/159.1.241

Tradewell, M. L., Yu, Z., Tibshirani, M., Boulanger, M. C., Durham, H. D., and Richard, S. (2012). Arginine methylation by prmtl regulates nuclearcytoplasmic localization and toxicity of FUS/TLS harbouring ALS-linked mutations. Hum. Mol. Genet. 21, 136-149. doi: 10.1093/hmg/ddr448

Tran, H., Almeida, S., Moore, J., Gendron, T. F., Chalasani, U. D., Lu, Y., et al. (2015). Differential Toxicity of Nuclear RNA Foci versus Dipeptide Repeat Proteins in a Drosophila Model of C9ORF72 FTD/ALS. Neuron 87, 1207-1214. doi: 10.1016/j.neuron.2015.09.015

Tsai, P.-I., Lin, C.-H., Hsieh, C.-H., Papakyrikos, A. M., Kim, M. J., Napolioni, V., et al. (2018). PINK1 Phosphorylates MIC60/Mitofilin to control structural plasticity of mitochondrial crista junctions. Mol. Cell 69, 744-756.e6. doi: 10.1016/j.molcel.2018.01.026

Tsai, Y.-L., Coady, T. H., Lu, L., Zheng, D., Alland, I., Tian, B., et al. (2020). ALS/FTD-associated protein FUS induces mitochondrial dysfunction by preferentially sequestering respiratory chain complex mRNAs. Genes Dev. 34, 785-805. doi: 10.1101/gad.335836.119

Tsuyama, T., Kishikawa, J., Han, Y.-W., Harada, Y., Tsubouchi, A., Noji, H., et al. (2013). In Vivo Fluorescent Adenosine 5'-Triphosphate (ATP) Imaging of drosophila melanogaster and caenorhabditis elegans by using a genetically encoded fluorescent ATP biosensor optimized for low temperatures. Anal. Chem. 85, 7889-7896. doi: 10.1021/ac4015325

Turner, M. R., Al-Chalabi, A., Chio, A., Hardiman, O., Kiernan, M. C., Rohrer, J. D., et al. (2017). Genetic screening in sporadic ALS and FTD. J. Neurol. Neurosurg. Psychiatry 88, 1042-1044. doi: 10.1136/jnnp-2017-315995

Van Blitterswijk, M., Dejesus-Hernandez, M., and Rademakers, R. (2012). How do C9ORF72 repeat expansions cause amyotrophic lateral sclerosis and frontotemporal dementia: can we learn from other noncoding repeat expansion disorders? Curr. Opin. Neurol. 25, 689-700. doi: 10.1097/WCO. ob013e32835a3efb

Van Langenhove, T., Van Der Zee, J., and Van Broeckhoven, C. (2012). The molecular basis of the frontotemporal lobar degeneration-amyotrophic lateral sclerosis spectrum. Ann. Med. 44, 817-828. doi: 10.3109/07853890.2012.665471

Vance, C., Lehmann, R., Broihier, H. T., Moore, L. A., Lehmann, R., Lehmann, R., et al. (2009). Mutations in FUS, an RNA processing protein, cause familial amyotrophic lateral sclerosis type 6. Science 323, 1208-1211. doi: 10.1126/ science.1165942.Mutations

Vandamme, T. (2014). Use of rodents as models of human diseases. J. Pharm. Bioallied Sci. 6, 2-9. doi: 10.4103/0975-7406.124301

Vargas, M. R., Johnson, D. A., and Johnson, J. A. (2011). Decreased glutathione accelerates neurological deficit and mitochondrial pathology in familial ALSlinked hSOD1(G93A) mice model. Neurobiol. Dis. 43, 543-551. doi: 10.1016/j. nbd.2011.04.025

Wang, J.-W., Brent, J. R., Tomlinson, A., Shneider, N. A., and McCabe, B. D. (2011). The ALS-associated proteins FUS and TDP-43 function together to affect Drosophila locomotion and life span. J. Clin. Invest. 121, 4118-4126. doi: $10.1172 / \mathrm{JCI} 57883$

Wang, L. J., Hsu, T., Lin, H. L., and Fu, C. Y. (2020). Drosophila MICOS knockdown impairs mitochondrial structure and function and promotes mitophagy in muscle tissue. Biol. Open 9:bio054262. doi: 10.1242/bio.054262

Wang, P., Deng, J., Dong, J., Liu, J., Bigio, E. H., Mesulam, M., et al. (2019). TDP43 induces mitochondrial damage and activates the mitochondrial unfolded protein response. PLoS Genet. 15:e1007947. doi: 10.1371/journal.pgen.1007947

Wang, T., Liu, H., Itoh, K., Oh, S., Zhao, L., Murata, D., et al. (2021). C9orf72 regulates energy homeostasis by stabilizing mitochondrial complex I assembly. Cell Metab. 33, 531-546.e9. doi: 10.1016/j.cmet.2021.01.005

Wang, W., Li, L., Lin, W. L., Dickson, D. W., Petrucelli, L., Zhang, T., et al. (2013). The ALS disease-associated mutant TDP-43 impairs mitochondrial dynamics and function in motor neurons. Hum. Mol. Genet. 22, 4706-4719. doi: $10.1093 / \mathrm{hmg} / \mathrm{ddt} 319$

Wang, W., Wang, L., Lu, J., Siedlak, S. L., Fujioka, H., Liang, J., et al. (2016). The inhibition of TDP-43 mitochondrial localization blocks its neuronal toxicity. Nat. Med. 22, 869-878. doi: 10.1038/nm.4130

Warren, J. D., Rohrer, J. D., and Rossor, M. N. (2013). Frontotemporal dementia. BMJ 347:f4827. doi: 10.1136/bmj.f4827

Warrick, J. M., Paulson, H. L., Gray-Board, G. L., Bui, Q. T., Fischbeck, K. H., Pittman, R. N., et al. (1998). Expanded polyglutamine protein forms nuclear inclusions and causes neural degeneration in Drosophila. Cell 93, 939-949. doi: 10.1016/s0092-8674(00)81200-3

Watts, G. D., Wymer, J., Kovach, M. J., Mehta, S. G., Mumm, S., Darvish, D., et al. (2004). Inclusion body myopathy associated with Paget disease of bone and frontotemporal dementia is caused by mutant valosin-containing protein. Nat. Genet. 36, 377-381. doi: 10.1038/ng1332

Wawersik, S., and Maas, R. L. (2000). Vertebrate eye development as modeled in Drosophila. Hum. Mol. Genet. 9, 917-925. doi: 10.1093/hmg/9.6.917

Wen, X., Tan, W., Westergard, T., Krishnamurthy, K., Markandaiah, S. S., Shi, Y., et al. (2014). Antisense proline-arginine RAN dipeptides linked to C9ORF72-ALS/FTD form toxic nuclear aggregates that initiate in vitro and in vivo neuronal death. Neuron 84, 1213-1225. doi: 10.1016/j.neuron.2014. 12.010

Whelan, J., Burke, B., Rice, A., Tong, M., and Kuebler, D. (2010). Sensitivity to seizure-like activity in Drosophila following acute hypoxia and hypercapnia. Brain Res. 1316, 120-128. doi: 10.1016/j.brainres.2009.12.036

Wiedemann, F. R., Manfredi, G., Mawrin, C., Beal, M. F., and Schon, E. A. (2002). Mitochondrial DNA and respiratory chain function in spinal cords of ALS patients. J. Neurochem. 80, 616-625. doi: 10.1046/j.0022-3042.2001.00 731.x 
Williams, K. L., Topp, S., Yang, S., Smith, B., Fifita, J. A., Warraich, S. T., et al. (2016). CCNF mutations in amyotrophic lateral sclerosis and frontotemporal dementia. Nat. Commun. 7:11253. doi: 10.1038/ncomms11253

Winton, M. J., Igaz, L. M., Wong, M. M., Kwong, L. K., Trojanowski, J. Q., and Lee, V. M.-Y. (2008). Disturbance of nuclear and cytoplasmic TAR DNAbinding protein (TDP-43) induces disease-like redistribution, sequestration, and aggregate formation. J. Biol. Chem. 283, 13302-13309. doi: 10.1074/jbc. M800342200

Witte, J. S. (2010). Genome-wide association studies and beyond. Annu. Rev. Public Health 31, 9-20. doi: 10.1146/annurev.publhealth.012809.103723

Wong, C.-O., Karagas, N. E., Jung, J., Wang, Q., Rousseau, M. A., Chao, Y., et al. (2021). Regulation of longevity by depolarization-induced activation of PLC$\beta$-IP3R signaling in neurons. Proc. Natl. Acad. Sci. U. S. A. 118:e2004253118. doi: $10.1073 /$ pnas. 2004253118

Woo, J. A., Liu, T., Trotter, C., Fang, C. C., De Narvaez, E., Lepochat, P., et al. (2017). Loss of function CHCHD10 mutations in cytoplasmic TDP-43 accumulation and synaptic integrity. Nat. Commun. 8:15558. doi: 10.1038/ ncomms 15558

Xiao, Y., Karam, C., Yi, J., Zhang, L., Li, X., Yoon, D., et al. (2018). ROS-related mitochondrial dysfunction in skeletal muscle of an ALS mouse model during the disease progression. Pharmacol. Res. 138, 25-36. doi: 10.1016/j.phrs.2018. 09.008

Xu, H., DeLuca, S. Z., and O'Farrell, P. H. (2008). Manipulating the metazoan mitochondrial genome with targeted restriction enzymes. Science 321, 575-577. doi: 10.1126/science.1160226

Xu, L., Liu, T., Liu, L., Yao, X., Chen, L., Fan, D., et al. (2020). Global variation in prevalence and incidence of amyotrophic lateral sclerosis: a systematic review and meta-analysis. J. Neurol. 267, 944-953. doi: 10.1007/s00415-019-09652-y

Xu, Z., Poidevin, M., Li, X., Li, Y., Shu, L., Nelson, D. L., et al. (2013). Expanded GGGGCC repeat RNA associated with amyotrophic lateral sclerosis and frontotemporal dementia causes neurodegeneration. Proc. Natl. Acad. Sci. U. S. A. 110, 7778-7783. doi: 10.1073/pnas.1219643110

Yan, J., Deng, H.-X., Siddique, N., Fecto, F., Chen, W., Yang, Y., et al. (2010). Frameshift and novel mutations in FUS in familial amyotrophic lateral sclerosis and ALS/dementia. Neurology 75, 807-814. doi: 10.1212/WNL. 0b013e3181f07e0c

Yang, D., Abdallah, A., Li, Z., Lu, Y., Almeida, S., and Gao, F.-B. (2015). FTD/ALSassociated poly(GR) protein impairs the Notch pathway and is recruited by poly(GA) into cytoplasmic inclusions. Acta Neuropathol. 130, 525-535. doi: 10.1007/s00401-015-1448-6

Yang, Y., Ouyang, Y., Yang, L., Beal, M. F., McQuibban, A., Vogel, H., et al. (2008). Pink1 regulates mitochondrial dynamics through interaction with the fission/fusion machinery. Proc. Natl. Acad. Sci. U. S. A. 105, 7070-7075. doi: 10.1073/pnas.0711845105

Yarosh, W., Monserrate, J., Tong, J. J., Tse, S., Le, P. K., Nguyen, K., et al. (2008). The molecular mechanisms of OPA1-mediated optic atrophy in drosophila model and prospects for antioxidant treatment. PLoS Genet. 4:e6. doi: 10.1371/journal. pgen.0040006

Yu, C.-H., Davidson, S., Harapas, C. R., Hilton, J. B., Mlodzianoski, M. J., Laohamonthonkul, P., et al. (2020). TDP-43 Triggers Mitochondrial DNA Release via mPTP to Activate cGAS/STING in ALS. Cell 183, 636-649.e18. doi: 10.1016/j.cell.2020.09.020

Zhang, J., Wang, Q., Wang, M., Jiang, M., Wang, Y., Sun, Y., et al. (2016). GASZ and mitofusin-mediated mitochondrial functions are crucial for spermatogenesis. EMBO Rep. 17, 220-234. doi: 10.15252/embr.20154 0846

Zhang, K., Coyne, A. N., and Lloyd, T. E. (2018). Drosophila models of amyotrophic lateral sclerosis with defects in RNA metabolism. Brain Res. 1693, 109-120. doi: 10.1016/j.brainres.2018.04.043

Zhang, Y. J., Gendron, T. F., Ebbert, M. T. W., O'Raw, A. D., Yue, M., JansenWest, K., et al. (2018). Poly(GR) impairs protein translation and stress granule dynamics in C9orf72-associated frontotemporal dementia and amyotrophic lateral sclerosis. Nat. Med. 24, 1136-1142. doi: 10.1038/s41591-018-0071-1

Zhang, K., Donnelly, C. J., Haeusler, A. R., Grima, J. C., Machamer, J. B., Steinwald, P., et al. (2015). The C9orf72 repeat expansion disrupts nucleocytoplasmic transport. Nature 525, 56-61. doi: 10.1038/nature14973

Zhang, Y., Schmid, B., Nikolaisen, N. K., Rasmussen, M. A., Aldana, B. I., Agger, M., et al. (2017). Patient iPSC-derived neurons for disease modeling of frontotemporal dementia with mutation in CHMP2B. Stem Cell Rep. 8, 648-658. doi: 10.1016/j.stemcr.2017.01.012

Zhang, Y.-J., Guo, L., Gonzales, P. K., Gendron, T. F., Wu, Y., Jansen-West, K., et al. (2019). Heterochromatin anomalies and double-stranded RNA accumulation underlie C9orf72 poly(PR) toxicity. Science 363:eaav2606. doi: 10.1126/science. aav2606

Conflict of Interest: The authors declare that the research was conducted in the absence of any commercial or financial relationships that could be construed as a potential conflict of interest.

Publisher's Note: All claims expressed in this article are solely those of the authors and do not necessarily represent those of their affiliated organizations, or those of the publisher, the editors and the reviewers. Any product that may be evaluated in this article, or claim that may be made by its manufacturer, is not guaranteed or endorsed by the publisher.

Copyright (c) 2021 Anoar, Woodling and Niccoli. This is an open-access article distributed under the terms of the Creative Commons Attribution License (CC BY). The use, distribution or reproduction in other forums is permitted, provided the original author(s) and the copyright owner(s) are credited and that the original publication in this journal is cited, in accordance with accepted academic practice. No use, distribution or reproduction is permitted which does not comply with these terms. 